\title{
Accuracy of Digital Impressions at Varying Implant Depths: An In- vitro Study
}

Vivia Sequeira

West Virginia University, vs0025@mix.wvu.edu

Follow this and additional works at: https://researchrepository.wvu.edu/etd

Part of the Dental Materials Commons, Periodontics and Periodontology Commons, and the Prosthodontics and Prosthodontology Commons

\section{Recommended Citation}

Sequeira, Vivia, "Accuracy of Digital Impressions at Varying Implant Depths: An In-vitro Study" (2021). Graduate Theses, Dissertations, and Problem Reports. 8038.

https://researchrepository.wvu.edu/etd/8038

This Thesis is protected by copyright and/or related rights. It has been brought to you by the The Research Repository @ WVU with permission from the rights-holder(s). You are free to use this Thesis in any way that is permitted by the copyright and related rights legislation that applies to your use. For other uses you must obtain permission from the rights-holder(s) directly, unless additional rights are indicated by a Creative Commons license in the record and/ or on the work itself. This Thesis has been accepted for inclusion in WVU Graduate Theses, Dissertations, and Problem Reports collection by an authorized administrator of The Research Repository @ WVU. For more information, please contact researchrepository@mail.wvu.edu. 
Graduate Theses, Dissertations, and Problem Reports

2021

Accuracy of Digital Impressions at Varying Implant Depths: An Invitro Study

Vivia Sequeira

Follow this and additional works at: https://researchrepository.wvu.edu/etd

Part of the Dental Materials Commons, Periodontics and Periodontology Commons, and the Prosthodontics and Prosthodontology Commons 


\title{
Accuracy of Digital Impressions at Varying Implant Depths: An In vitro Study
}

\author{
Vivia Sequeira, B.D.S. \\ in partial fulfillment of the requirements for the Degree of \\ Master of Science in Prosthodontics \\ Matthew T. Harper, D.D.S., M.S (Chair) \\ Matthew S. Bryington, D.M.D., M.S., FACP \\ Shelby Alexander, D.D.S., M.S., FACP \\ Bryan Weaver, D.D.S., M.D. \\ The Department of Restorative Dentistry \\ Morgantown, West Virginia
}

May 2021

Keywords: Accuracy, CAD CAM, Digital Impression, Intraoral Scan body, Intraoral Scanners, Implant, Depth

Copyright 2021 Vivia Sequeira 


\title{
ABSTRACT \\ Accuracy of Digital Impressions at Varying Implant Depths: An In-vitro Study
}

\author{
Vivia Sequeira, BDS
}

Introduction: Implants placed at variable depths may vary the amount of visible scannable surface of a scan body. Intraoral scanner technology uses advanced optical principles to record the surface of the scan body to accurately capture the implant position.

Purpose: To investigate the effect implant placement depth has on the accuracy of digital implant impressions using an intraoral scanner.

Materials \& Methods: A partially edentulous gypsum master model was fabricated to allow the positioning of a single implant analog at different depths. Four groups based on the planned implant depths of $0,3,6$ and $7 \mathrm{~mm}$ and corresponding visibility of the scan body at 9, 6, 3 and $2 \mathrm{~mm}$ were created. The model was digitized with a laboratory scanner for the reference scan and with an intraoral scanner to generate 15 test scans per group. The test scans were superimposed onto the reference scan using the best fit algorithm to analyze and measure the positional (dXYZ) and angular deviation $(\mathrm{d} \theta)$ of the scan body using 3D metrology software. Statistical analysis was performed using a One way ANOVA and pairwise comparison was done with a Tukey-Kramer HSD test. ( $\alpha=$ $.05)$

Results: The one-way analysis of variance of the groups for the dXYZ and $d \theta$ parameters was statistically significant $(\mathrm{P}<0.0001)$. The $9 \mathrm{~mm}$ group showed the least positional deviation at $38.41 \mu \mathrm{m}(95 \% \mathrm{CI} 30.26 ; 46.56)$ and the least angular deviation of $0.17^{\circ}(95 \%$ CI $0.12 ; 0.21)$. The greatest positional deviation of $77.17 \mu \mathrm{m}(95 \% \mathrm{CI} 65.23 ; 89.11)$ and greatest angular deviation of $0.84^{\circ}(95 \%$ $0.65 ; 1.03$ ) was noted with the $2 \mathrm{~mm}$ group. The positional and angular deviation increased with increased implant depth.

Conclusions: The accuracy of digital impressions is influenced by the implant depth and the amount of visibility of the scan body. The trueness and precision of the digital impressions are highest when the implant is placed at $0 \mathrm{~mm}$ depth with complete visibility of the scan body and decreases with subgingival implant placement. 


\section{ACKNOWLEDGEMENTS}

I offer my sincere gratitude and appreciation to my Committee and all who helped me successfully complete this study.

Dr. Matthew S. Bryington for conceiving the idea and your unselfish support.

Dr. Matthew T. Harper for your valuable input especially in the past few months.

Dr. Bryan Dye, Dr. Shelby Alexander and Dr. Bryan Weaver for readily sharing your knowledge and contribution.

Dr. Laura Yura Godwin for generously lending the Caresteam IOS in times of great need and being very supportive. Carmella Meadows for your generous time and help with the scanner.

The Capture 3D team especially Drew Cook for listening attentively, taking a special interest in my project and assisting me with the GOM Inspect Suite software.

Dr. Christa Lilly for your time and invaluable help. I greatly appreciate your kindness and passion for what you do.

Charles Wisser for the quick IT support and constant technical help throughout the study.

Lyndsey Gray, our implant coordinator for your prompt help always.

My colleagues Dr. Caitlin Libby and Dr. Michele Agusto for your constant support and motivation.

And to my dear parents, Victor and Vinna Sequeira none of this would have been possible without you 


\section{TABLE OF CONTENTS}

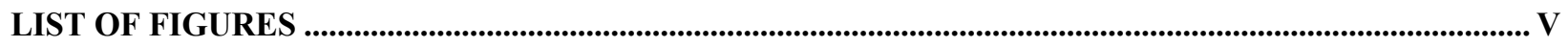

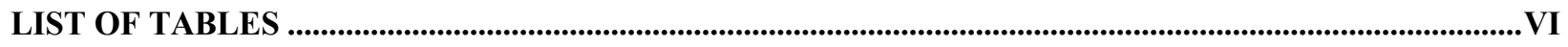

LIST OF ABBREVIATIONS........................................................................................................................................ VII

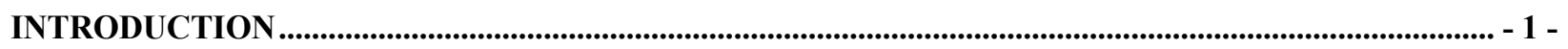

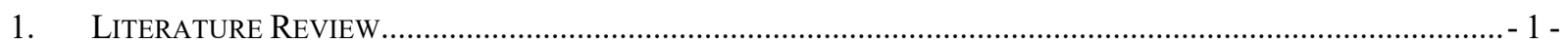

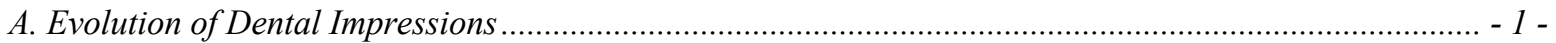

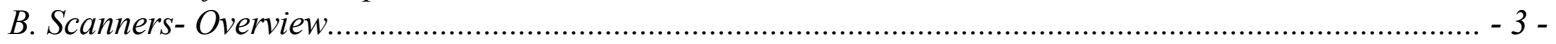

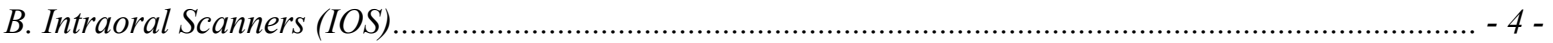

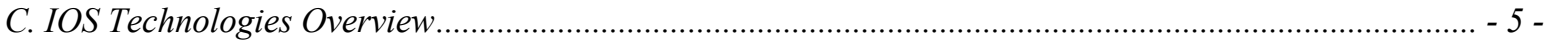

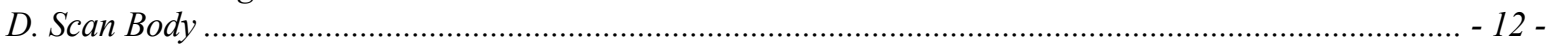

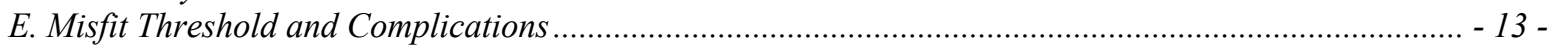

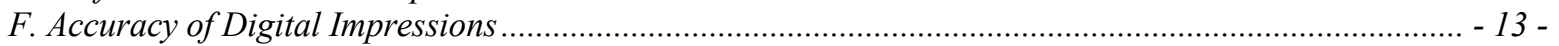

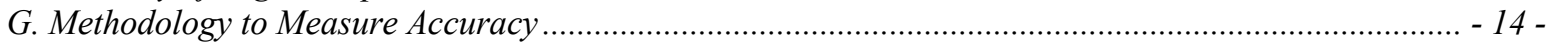

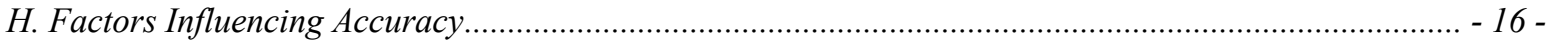

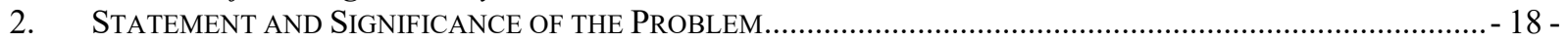

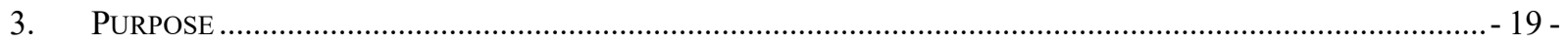

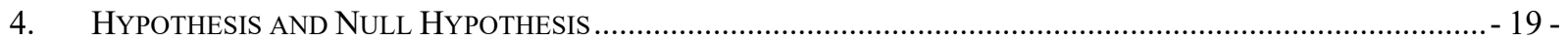

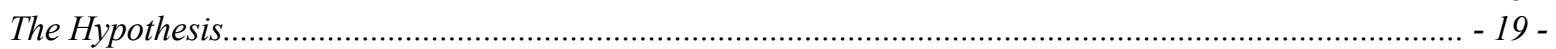

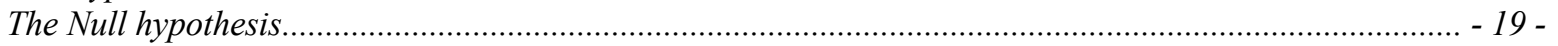

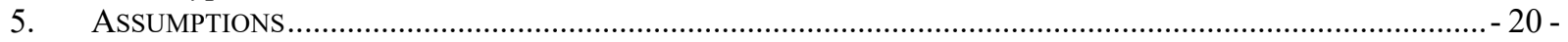

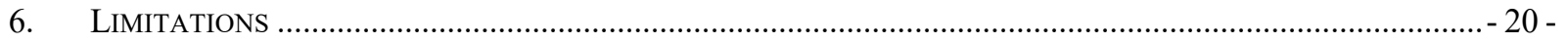

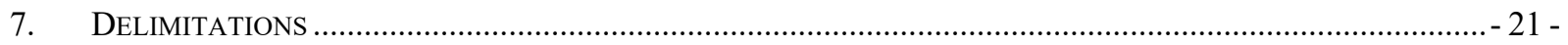

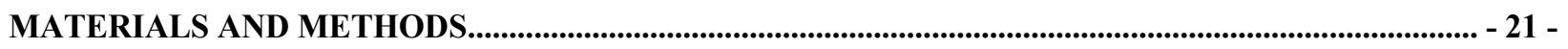

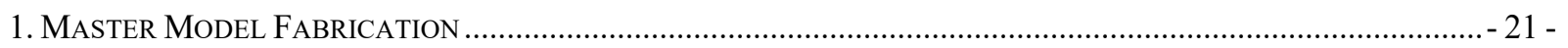

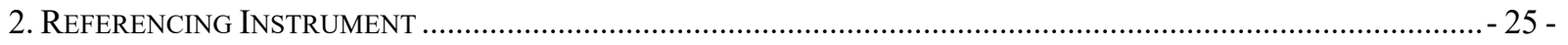

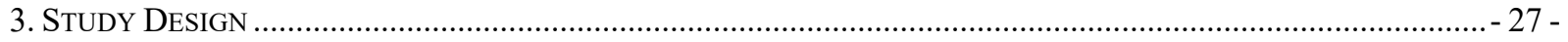

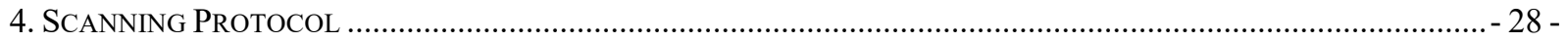

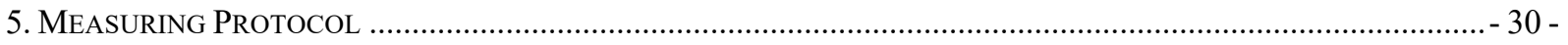

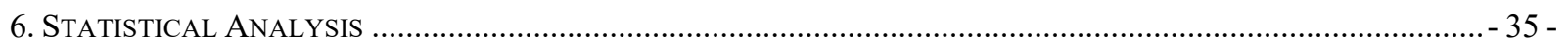

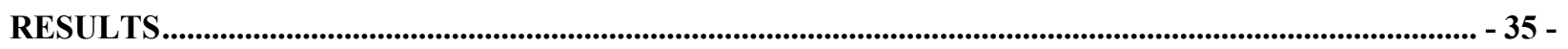

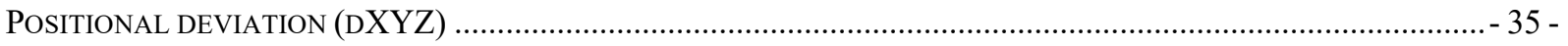

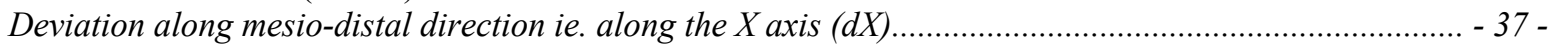

Deviation along bucco-lingual direction ie. along the $Y$ axis $(d Y)$......................................................... - 38 -

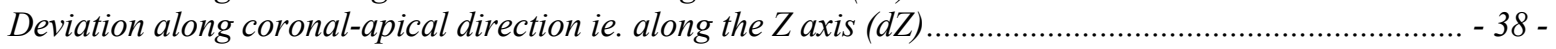

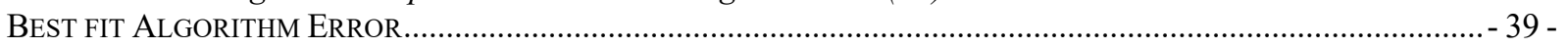

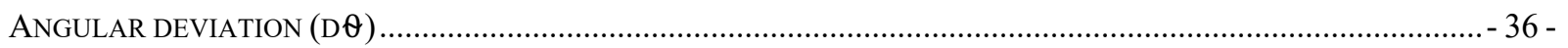

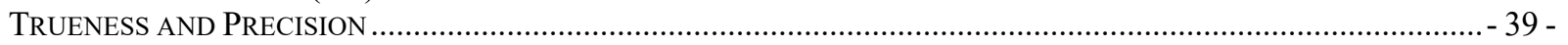

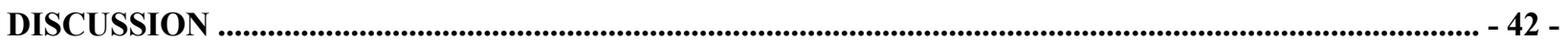

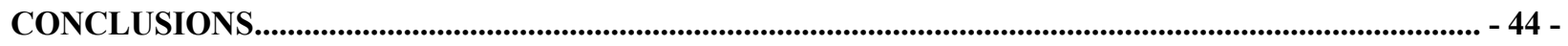

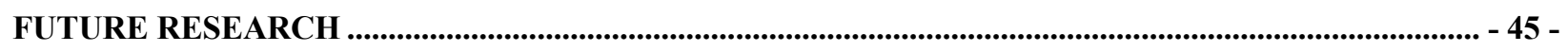

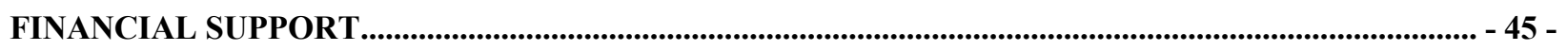

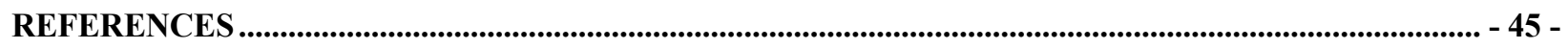




\section{LIST OF FIGURES}

Figure 1: Geometry behind the 3D data capture using the principle of triangulation. ${ }^{18}$...........- 6 Figure 2: Accordian Fringe Interferometry technology by modulation of fringe spacing to improve the accuracy of the optical impression. ${ }^{17}$................................................................ 7 Figure 3:A. Photogrammetry technique for surface mapping from 2D images taken from different views. ${ }^{14}$ B. PiC Dental LLC's extraoral scanner for intraoral implant impressions using the stereophotogrammetric technique. ${ }^{21}$................................................................... 8 -

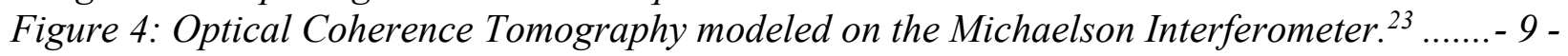
Figure 5: Geometry behind the 3D data capture using the principle of active and passive wavefront sampling to sample out-of-focus rays. ${ }^{25}$....................................................... 10 Figure 6: Confocal imaging technology to modulate focal lens to capture in focus rays. ${ }^{26}$.... - 11 -

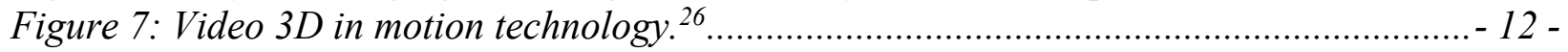
Figure 8: Master Impression of the partially edentulous maxillary arch. ............................. 22 Figure 9: Modified Implant analog ......................................................................... 22 Figure 10: A. Isolation of the left quadrant with beading wax. B. Implant analog in position.. - 23

Figure 11: A. Wax cube spacer. B. Recess in the base for VPS putty jig. $-24-$ Figure 12: A. Customised reference scale. B. Point of contact of reference scale on the model. $C$. Surveyor table fixed to the horizontal base. D. Master Model with reference markers. E. Corresponding reference markers on the surveyor table holder. F. Reference markers on the vertical spindle. $27-$ Figure 13: VPS jigs to fix the implant analog at the planned depths. $-28-$ Figure 14: A: Group 2mm implant analog placed 4mm depth subcrestal. B: Group 3mm with implant analog placed $3 \mathrm{~mm}$ subcrestal. C: Group $6 \mathrm{~mm}$ with implant analog placed equicrestal. D: Group 9mm with implant analog placed at soft tissue level. - 29 Figure 15: A: Zfx III Laboratory Scanner. B: Carestream CS3600 IOS. C: Reference scan for the $3 \mathrm{~mm}$ group. D: Test scan for the $9 \mathrm{~mm}$ group ...................................................................- 30 Figure 16. $2 \mathrm{~mm}$ group: The reference model was oriented to the local coordinate system. Best fit alignment was performed of the reference and test scan. Nominal elements consisting of a cylinder, plane and an intersection point were constructed to measure positional and angular deviation..... $32-$ Figure 17. 9mm group: The reference model was oriented to the same local coordinate system. Best fit alignment was performed of the reference and test scan. Nominal elements consisting of a cylinder, plane and an intersection point were constructed to measure positional and angular deviation. - 33 Figure 18. Zoomed view of the discrepancy between the constructed nominal elements corresponding to the scan body cylinder of the reference and test scans in the $9 \mathrm{~mm}$ and $3 \mathrm{~mm}$ groups. - 34 - 


\section{LIST Of TABLES}

Table 1: Variability Summary for dXYZ in $\mu m$ (positional deviation)................ 35 Table 2:Variability Summary for $d \theta$ in degrees (angular deviation) ................ - 36 Table 3: Variability Summary for $d X$ in $\mu m$ (deviation along the mesio-distal

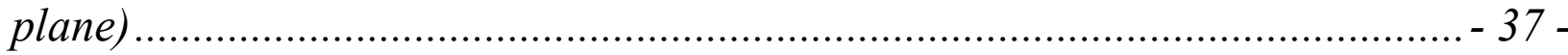

Table 4: Variability Summary for $d Y$ in $\mu m$ (deviation along the bucco-lingual

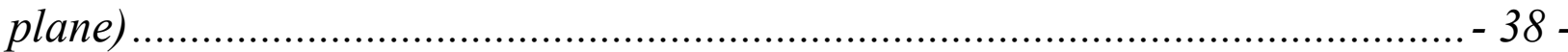

Table 5: Variability Summary for $d Z$ in $\mu m$ (deviation along the corono-apical plane)..... - 38 -

Table 6: A: $d X Y Z$ and $B: d \theta$. Heterogeneity of Variance tested. The standard deviation values lying closer to the lower limit indicate trueness. The $9 \mathrm{~mm}$ group shows the highest trueness compared to the 2 and $3 \mathrm{~mm}$ groups for both parameters. $d \theta$ values in the $9 \mathrm{~mm}$ group are lower than the lower limit indicating values very close to the reference scan. $-40-$ Table 7: A: $d X, B: d Y C: d Z$, Heterogeneity of variance tested. The standard deviation values lying closer to the lower limit indicate trueness. The $9 \mathrm{~mm}$ group shows the highest trueness compared to the other groups, especially along the $Y$ axis. 


\section{LIST OF ABBREVIATIONS}

CAD-CAM: Computer Aided Design and Computer Aided Manufacturing

CEREC: Chairside Economic Restorations of Esthetic Ceramics

CMM: Coordinate Measuring machine

IOS: Intraoral Scanner

STL: Standard Tessellation Language

PLY: Polygon File Format

LASER: Light Amplification by Stimulated Emission of Radiation

CCD: Charge Coupled Device

CMOS: Complementary metal oxide semiconductor

AFI: Accordion Fringe Interferometry

2D: Two Dimensional

PEEK: Polyether ether Ketone

VPS: Vinylpolysiloxane

3D: Three Dimensional

$\mathrm{RC}$ : Regular CrossFit ${ }^{\circledR}$

SCS: Screw Carrying System

ISO: International Organization for Standardization

TAN: Titanium alloy consisting of Titanium-Aluminum-Niobium (Ti6A17Nb)

LED: Light Emitting Diode

CSV: Comma Separated Values

$\mathrm{dXYZ}$ : Positional deviation along $\mathrm{X}, \mathrm{Y}$ and $\mathrm{Z}$ axis

$\mathrm{dX}$ : Positional deviation along $\mathrm{X}$ axis

$\mathrm{dY}$ : Positional deviation along $\mathrm{Y}$ axis

$\mathrm{dZ}$ : Positional deviation along $\mathrm{Z}$ axis

$\mathrm{d} \theta$ : Angular deviation 


\section{INTRODUCTION}

\section{Literature Review}

\section{A. Evolution of Dental Impressions}

The evolution of dental impression materials began in the late 1700 s with beeswax being the first impression material to be used intraorally. Plaster of Paris, waxes and modeling compound were popular for a large part of the next century. Various materials were introduced including reversible hydrocolloids, zinc oxide eugenols and alginates while impression concepts and techniques continued to evolve in the early 1900s. By the late 1950s, polysulfide and silicone-based elastomeric impression materials were developed and became the preferred materials in fixed prosthodontics and complete denture impressions. ${ }^{1}$

According to the American Dental Association No.19 specification, the elastomeric impression materials should accurately reproduce details of $20 \mu \mathrm{m}$ for all viscosities except very high viscosity materials that should reproduce details of $75 \mu \mathrm{m} .^{2}$

Due to the high level of accuracy in reproducing fine details as well as the dimensional stability of the materials, elastomeric impression materials are widely used today in all aspects of prosthodontics including implant prosthodontics. ${ }^{3}$

The advent of CAD-CAM with the introduction of the Duret system by Dr. Francois Duret in the 1970s ushered in a new era in dentistry. On November 30 1985, at the International Congress of the French Dental Association he demonstrated the fabrication of a posterior crown for his wife using the Duret 
system in less than an hour! ${ }^{4}$ Multiple systems that followed, like the CEREC system (Today, Dentsply Sirona) developed by Dr. Mörmann and Brandestini sought to digitize the process of acquisition of impressions, designing and fabrication of the restoration. Milling of restorations along with an on-site sintering device eliminated the issues associated with the labor intensive lost wax technique and provided the benefit of fabricating restorations on the same day in office. ${ }^{5}$ The CAD steps involved image acquisition technologies that ranged from electrooptical methods that combined holography and moiré fringe technique using a laser light source and a camera, to mechanical pantograph stylus type digitizers using photogrammetry. This was followed by visualization and modification of the virtual model on a computer screen and designing the prosthesis using dedicated software. The CAM process involved the fabrication of the final restoration from milling blocks using a computerized milling tool. ${ }^{5,6}$

The CAD-CAM system sought to overcome the challenges faced with conventional impression making and fabrication of the prosthesis particularly to minimize or eliminate the errors inherent to the conventional workflow:

- Those associated with adhesive, tray selection and impression materials with polymerization shrinkage, tearing and distortion, transport and storage of impressions.

- Incorporation of voids during model fabrication, gypsum stone expansion

- Dimensional changes during casting and veneering in the ceramic furnace. $3,7,8,9$

Several additional advantages of digital impressions include:

- Reduced patient discomfort particularly in cases of a strong gag reflex and better clinical efficiency ${ }^{10}$ 
- Error correction by selective editing and rescanning

- An evaluation tool to evaluate and modify the tooth preparation

- Virtual file for digital workflow continuum

- Reduced armamentarium and time for impression making

- Eliminate the risk of infection transmission

- Rapid and enhanced laboratory communication

- Digital storage and archiving of records

- Real time patient educational tool

- Follow up tool

- Increased laboratory turnover time and overall efficiency

- Reduced long-term costs. ${ }^{11,12}$

\section{B. Scanners- Overview}

Scanners are a medium to digitize the object, where digitization is the process of gathering the requisite data from an object. Scanning acquisition technologies can perform surface profiling using a contact method like the CMM machines that use a touch probe that contacts the surface to be scanned to measure the relative position of the points on the object's surface. The non-contact method uses a more compact device and is faster than the contact method. IOS and laboratory scanners are non-contact scanning devices that use optical principles of light projection and reflection to gather surface point data. ${ }^{13}$

Digital impressions can be obtained in two ways, a direct technique utilizes an intraoral scanner to digitize the arch whereas an indirect technique utilizes a dental laboratory scanner to digitize the cast obtained from a conventional impression or the impression itself. 
This offers flexibility to jump in and out at any point in the digital workflow of fabricating a prosthesis.

\section{B. Intraoral Scanners (IOS)}

An IOS is an intraoral three-dimensional data acquisition system that consists of a compact handheld device usually referred to as a scanning wand with an inbuilt light source and camera used to 3D map the oral tissues. The wand is capable of projecting the light on the surface of the tissue and is recorded using a camera as still images or continuous video data sets or point clouds containing multiple points of interest. The spatial location of the surface points in two coordinates is recorded and the third coordinate is calculated using a specific distance to object principle to obtain the $3 \mathrm{D}$ coordinates of the points and subsequently the entire surface.

The point cloud data is instantly transferred to a computer that uses specific image processing and $3 \mathrm{D}$ reconstruction algorithms to identify image overlaps and stitches them together, filters unwanted data points to reduce noise and generate a 3D model of the tissue surface. It is important to respect the scanning strategies recommended by the manufacturer to allow the scanner to track and maintain spatial orientation and identify sufficient points of interest from the previous image to reconstruct the model accurately. The model can be viewed in real time on the IOS monitor and using virtual editing tools can be trimmed, imperfect areas can be edited and rescanned and reviewed for further processing. ${ }^{14,15,16}$

The 3D model is called a mesh that consists of a collection of polygon flat planes formed by connecting 3D vertices. ${ }^{17}$ For the sake of simplification and ease of analysis and processing, the polygon mesh is converted into a triangle mesh and stored in a digital format called STL (Standard Tessellation Language) that may be an open or a locked STL format. The open format offers the advantage of using an 
alternate software beyond the proprietary scanner software. The STL format consists of a conglomeration of triangulated surfaces where each triangle is defined by three points and a normal surface. Other file formats like Polygon File Format (PLY) have been developed to additionally record the color, transparency, or texture of dental tissues. ${ }^{14}$

\section{IOS Technologies Overview}

Various distance to object principles employed in the current IOS systems is the principle of triangulation, wavefront sampling, confocal imaging, stereophotogrammetry, interferometry and active $3 \mathrm{D}$ video to name a few.

\section{Principle of triangulation}

This principle is based on trigonometry where a line formed by two points fixed at a known distance with two known angles projecting from those points helps determine the position of the third point forming a triangle. The distance between

the light source and the sensor ie. a CCD or a CMOS sensor is fixed. The projected beam or fringe pattern from the light source illuminates a point on the surface of the oral tissue and backscatters. The reflected rays from the surface points are focused by a lens on an image sensor. As the relation of the tissue surface with respect to the light source-sensor complex changes, the points get recorded at different positions on the sensor and the shift is measured to calculate the coordinates of the surface points. (Figure 1) In active triangulation, as seen in the CEREC system (Dentsply Sirona), a structured light source like a white light or a blue light projects a fringe pattern across the scanning surface. The rapid shift of the pattern in each scan is captured by the camera to measure the $3 \mathrm{D}$ coordinates of the surface points. ${ }^{4,14}$ 


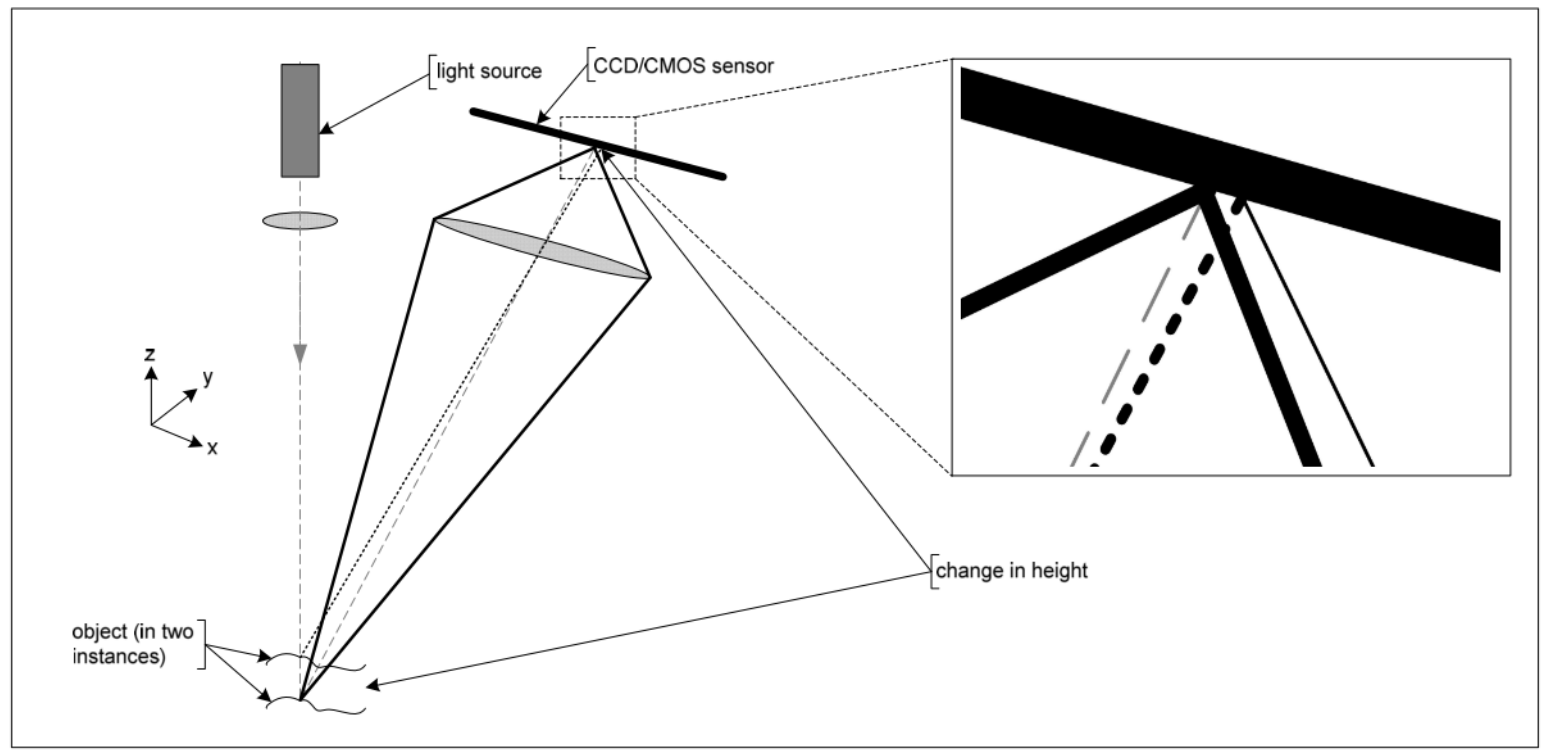

Figure 1: Geometry behind the $3 D$ data capture using the principle of triangulation. ${ }^{18}$

\section{Accordion Fringe Interferometry (AFI)}

This surface profiling technique is a type of active triangulation process based on projecting interference fringes onto the tissue surface. This sinusoidal fringe pattern is formed by interference from two coherent laser point sources set at one location with the viewing camera set at another location. A fine fringe pattern leads to high accuracy. The system modulates the fringe pattern by first projecting very coarse fringes onto the object to obtain a rough estimate of the surface topology. The fringes are further refined to provide accurate surface mapping. Interference fringes have the advantage of the infinite depth of field, which allows large or complex objects to be illuminated without the need for source focus and is less sensitive to ambient light that results in better accuracy with varied surface textures. ${ }^{19}$ ( Figure 2)

Lythos $^{\mathrm{TM}}$ Digital Impression System (Ormco Corporation) is modeled on the AFI technology. 


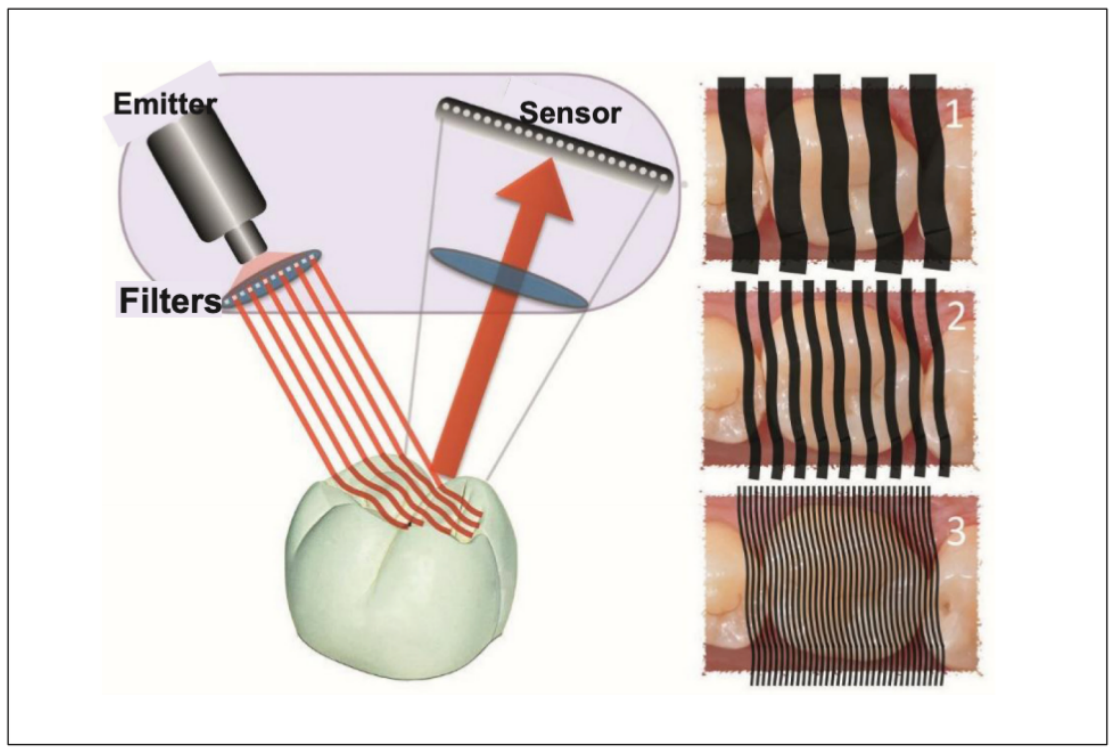

Figure 2: Accordian Fringe Interferometry technology by modulation of fringe spacing to improve the accuracy of the optical impression. ${ }^{17}$

\section{Stereophotogrammetry}

Stereophotogrammetry is a form of passive triangulation that commutes accurate coordinate measurements using photogrammetric algorithms from a series of quick 2D photographs of the tissue surface obtained from multiple cameras with an ambient light source. The angulation of the cameras and the distance between them is known. Images are captured from various angles with reference markers present in the field of view to constantly calibrate the images. The images from the different views are matched and the displacement of the target surface between the two images is measured. Utilizing the principles of triangulation and 3D reconstruction algorithms, precise points are calculated onto the $3 \mathrm{D}$ coordinate plane and the 3D model of the tissue surface is created. ${ }^{4,20}$ ( Figure 3A) PiC system (Precise Implant Capture, PIC dental LLC Miami, FL) uses custom manufactured scan bodies for every implant platform with four calibration dots with a photogrammetry code to capture the implant positions and merge the scan 
with a soft tissue scan obtained from an IOS or with conventional impressions. ${ }^{21}$ (Figure 3B)
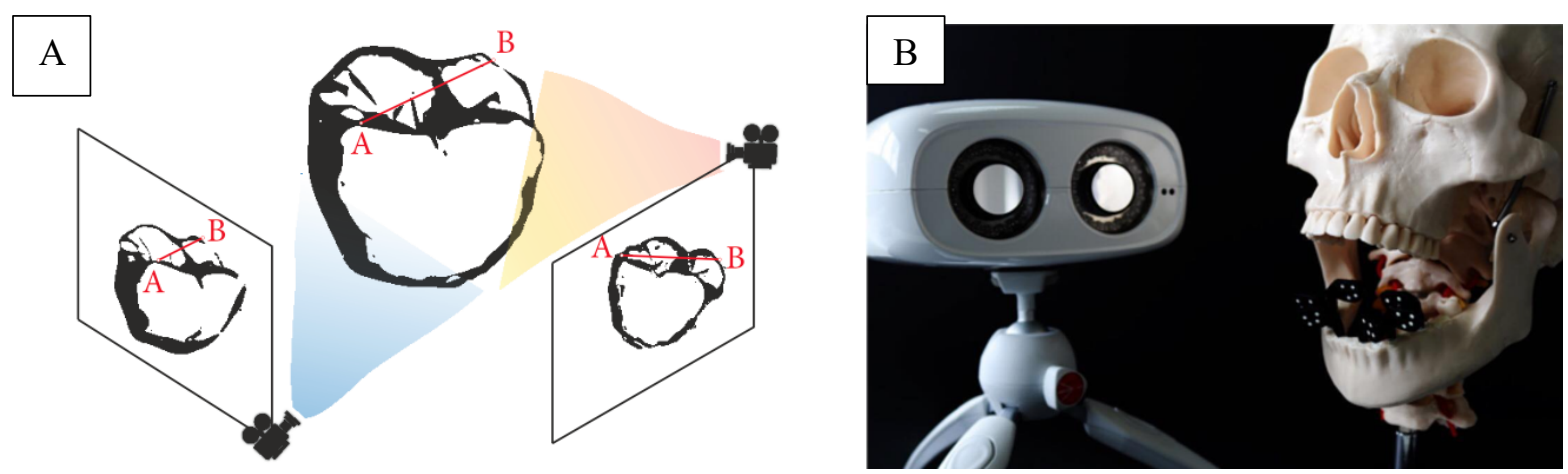

Figure 3:A. Photogrammetry technique for surface mapping from 2D images taken from different views. ${ }^{14} \mathrm{~B}$. PiC Dental LLC's extraoral scanner for intraoral implant impressions using the stereophotogrammetric technique. ${ }^{21}$

\section{Optical Coherence Tomography based on Interferometry}

The interferometry principle uses a beam splitter to split the laser light source into a reference arm that is reflected back to a photodetector using a reflecting mirror and a sample arm that passes through the beam splitter and is projected onto the scanned tissue surface. The sample arm when reflected off the object combines and interferes with the reference arm creating an interference fringe pattern that is recorded by the photodetector.

This system employs a laser light source of known wavelength and a photodetector offset at an angle from the light source. The photodetector is able to distinguish between the known wavelength of the reference arm compared to that of the fringe pattern. By varying the position of the reflecting mirrors and the subsequent variation in the fringe patterns generated the $3 \mathrm{D}$ coordinates of the points on the surface of the scanned tissue is calculated using triangulation principles to map it accurately. ${ }^{22}$ (Figure 4) 


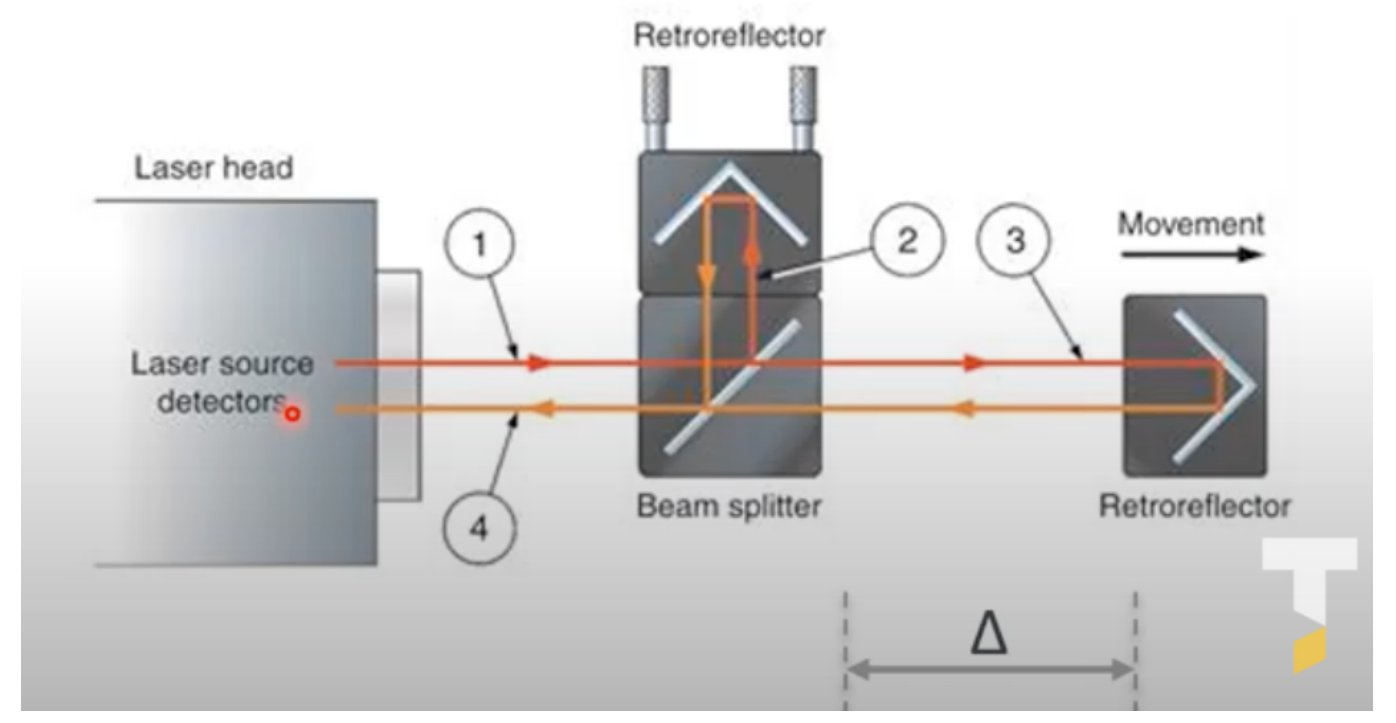

Figure 4: Optical Coherence Tomography modeled on the Michaelson Interferometer. ${ }^{23}$

\section{Wavefront Sampling}

This technology uses an off-axis rotating element with an aperture to sample the reflected out-of-focus rays of a surface point at different time intervals due to the rotating nature of the aperture element. The sampled rays cast a blurred image on the sensor, with the images of the surface points lying along the circumference of the blur spot. The diameter of the blur spots varies depending on the distance of the surface points from the sensor and the difference in depth can be calculated accordingly. With the $\mathrm{X}, \mathrm{Y}$ coordinates of the surface points known, the $\mathrm{Z}$ coordinate is measured using the focal and out of focus distance and the law of similar triangles. Passive wavefront sampling uses a multiple aperture element instead of a single aperture that records distinct images of the points separated by the distance corresponding to the diameter of the out-of-focus blur image. ${ }^{20,24}$ Image sensitivity is improved in this system due to capture of multiple images of a single point overlapping of images is avoided since a particular wavelength is sampled at a time. Active wavefront sampling is used in the Lava COS scanner. 


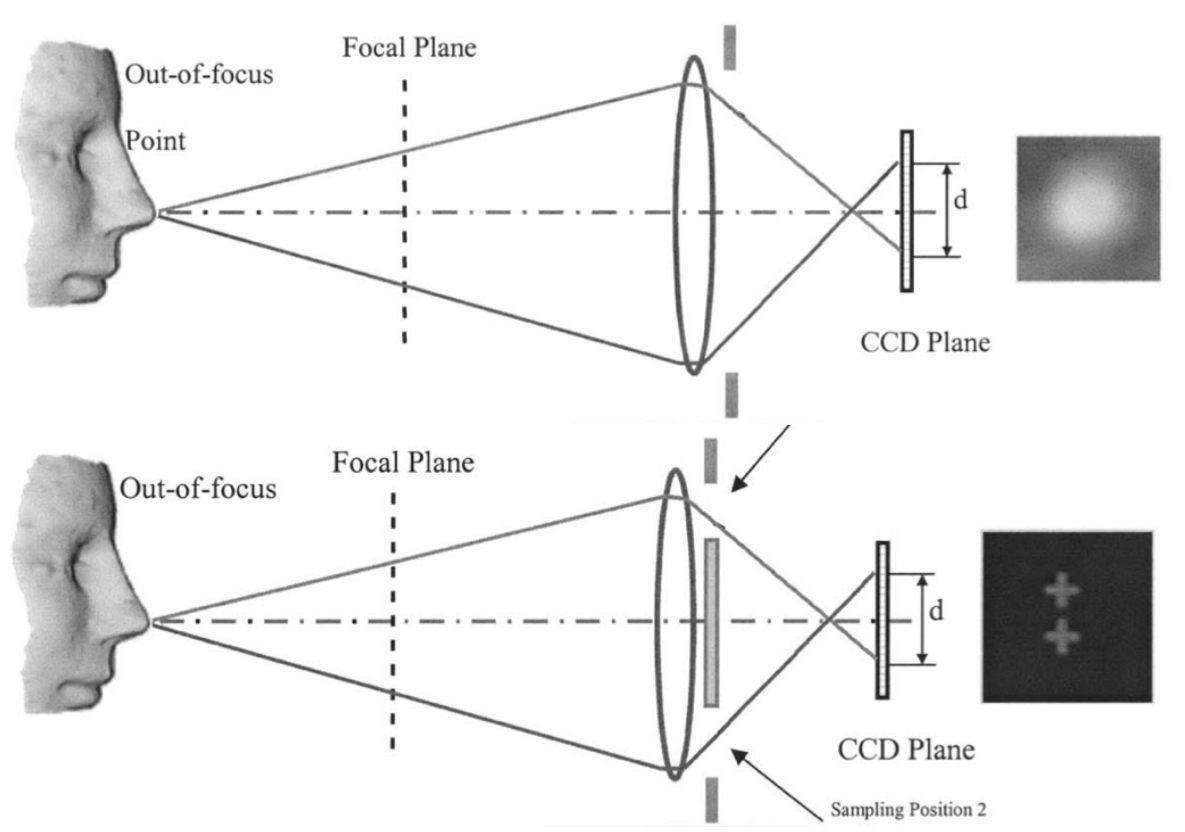

Figure 5: Geometry behind the 3D data capture using the principle of active and passive wavefront sampling to sample out-of-focus rays. ${ }^{25}$

\section{Confocal Imaging}

This technology consists of a monochromatic laser beam that is projected onto the tissue surface to obtain images with high resolution and in-depth sensitivity using a system of focal lenses to create multiple focal planes. As the beam is reflected off the surface it is guided through a lens assembly onto a beam splitter to the focal filter to allow passage of rays reflected from points lying only within the focal planes of the lenses and filtering out all the out of focus rays. The rays projected onto the sensor records the image of the points and its coordinates. The distance from the scanned part to the lens is the focal distance of the lens and the measure of the third coordinate of the point. To capture the entire object the lens is moved accordingly. The iTero Element (Align Technology, Inc. San Jose, CA) and TRIOS (3Shape A/S, Copenhagen, Denmark) uses parallel confocal imaging 
technology. The TRIOS scanner introduced a variation in the confocal principle with a time-dependent illumination pattern and focal plane positions while maintaining a fixed source-object-camera distance and the property of telecentricity to maintain the magnification of the images. $14,20,26$

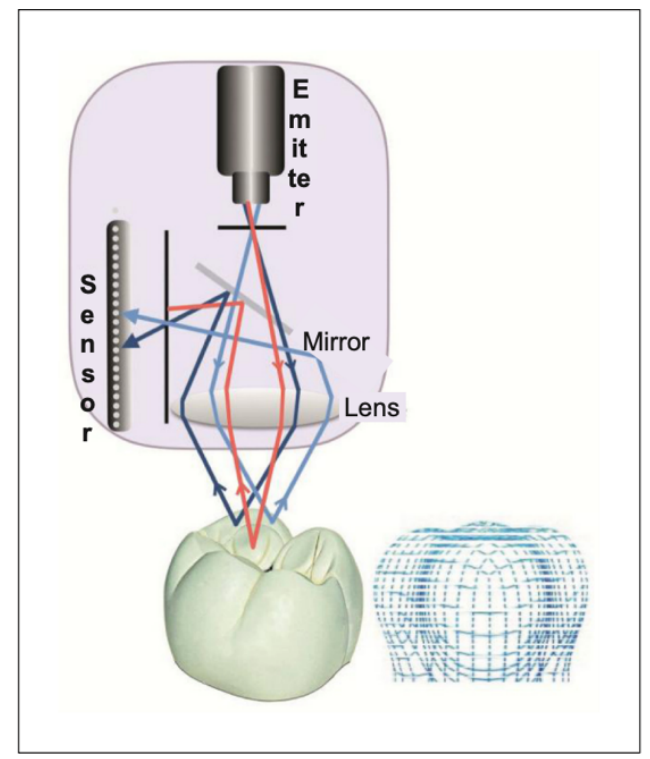

Figure 6: Confocal imaging technology to modulate focal lens to capture in focus rays. ${ }^{26}$

\section{Video $3 D$ in motion technology}

This system uses high-definition video cameras separated at a fixed distance to capture images in real time of the tissue surface from different views. These images are reassembled after computing the coordinates of the surface points using specific algorithms to create the 3D model. True definition Scanner (3M ${ }^{\mathrm{TM}}$ St Paul, $\mathrm{MN}$ ) and CS 3600 (Carestream Dental LLC.) use this technology. ${ }^{26}$ 


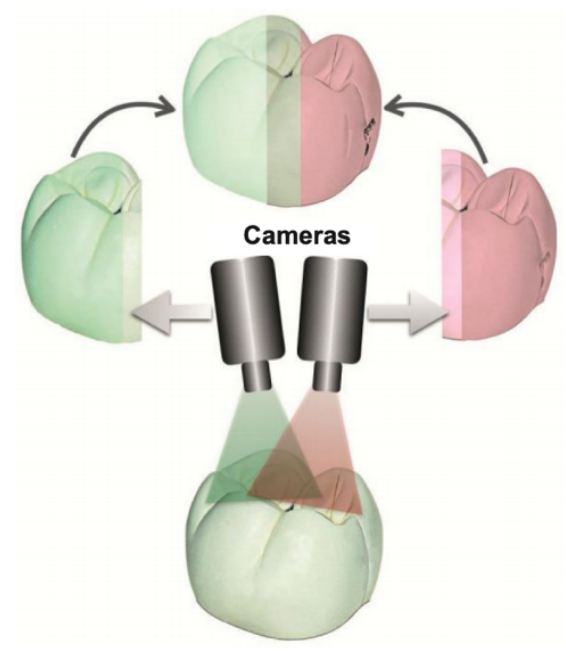

Figure 7: Video 3D in motion technology. ${ }^{26}$

\section{Scan Body}

The scan body is a scannable impression coping at the implant or abutment level with a unique multi-surface geometry to help index and virtually position the corresponding implant analog three-dimensionally within the CAD model. ${ }^{27}$ It consists of three parts, the upper portion consists of a unique surface feature called the scan region, the middle portion is the body of the coping and the lower portion is the base that contains the proprietary connection features that help engage the internal or external connection of the implant. The material composition can vary from polyether ether ketone (PEEK), titanium alloy, aluminum alloy, various resins or a combination of these materials. ${ }^{15}$ It may be a one-piece abutment or a two-piece abutment or a modified digitally coded healing abutment $\left(\right.$ Encode $^{\circledR}$, Biomet 3i, FL). The retention mechanism can differ from a fixture level screw retention to an abutment level magnetic retention. The intraoral scan body is limited in length due to oral space constraints. Most manufacturers recommend finger tightening the scan body with the driver with a maximum torque force of $15 \mathrm{Ncm}$ while connecting it to the implant. ${ }^{28}$ 


\section{E. Misfit Threshold and Complications}

The machining tolerance or the misfit is the interface gap between matched implant components from the same manufacturer in the horizontal plane. Tolerance of magnitude in the range of 22 to $100 \mu \mathrm{m}$ was found in a study by Ma.T et al 1997. ${ }^{29}$ To investigate the effects of this machining tolerance on the biological structures, Michaels. G.C et al studied the effect of prosthetic superstructure misfit of $466 \pm 209 \mu \mathrm{m}$ on the biologic tissue response in a rabbit tibia model and found no significant difference in the percent length and area of osseointegration of the implants. ${ }^{30}$ In a five year follow-up study in 1996, Jemt T. et al reported a marginal discrepancy of $111 \mu \mathrm{m}$ with a maximum of $275 \mu \mathrm{m}$ with no significant marginal bone loss and concluded that a certain biologic tolerance for prosthesis misfit may be present. ${ }^{31}$ A recent integrative review concluded that most of the studies reviewed had lower mean values of prosthesis misfit of implant supported structures manufactured by conventional casting that ranged from $50-160 \mu \mathrm{m} .{ }^{32}$ The mechanics of the prosthesis is compromised in cases of prosthesis misfit, marked by poor stress distribution with increased off-axis loads and stress concentration at the prosthetic and implant interface that can disrupt the mechanical connection of the abutment screw with the implant leading to screw loosening or a catastrophic fracture of the screw, implant or the prosthesis. ${ }^{33,34}$ Biological complications include the risk of incidence of peri-implant pathology. ${ }^{35}$ While there is no clear consensus on the acceptable level of misfit, to avoid adverse biological and mechanical complications, it is important to optimize the fit of the restorations. ${ }^{36}$

\section{F. Accuracy of Digital Impressions}


Research efforts are geared towards improving the technologies behind the IOS scanners and minimizing the errors at every step in the digital workflow that can adversely affect the final fit of the prosthesis. Minimizing the errors in the upstream process begins with obtaining an accurate impression of the scan body. To facilitate the next step of the CAD process, the scanned image of the scan body is transferred to dental CAD software that has access to the implant manufacturer's CAD files of the scan body and implant analogs. ${ }^{37}$ These CAD files contain the proprietary design or $3 \mathrm{D}$ rendering of the manufactured part. ${ }^{38}$ The dental CAD software uses proprietary alignment algorithms like the best fit algorithm to align the two images and orients the implant analog accordingly in the virtual dental model. Best fit is a nonspecific alignment that accounts for every point in the scanned image to globally minimize the distance of every measured point to its CAD reference. ${ }^{39}$ The discrepancy in the amount of scanned surface of the scan body and the CAD file affects the alignment process and the analog position. ${ }^{37}$ Thus, unimportant data points and the quality of the scanned image contributes to the accuracy of the workflow. Determining how digital technology can be employed and identifying the factors related to scan body acquisition can reduce the propagation of errors in the digital workflow ultimately translating into an accurately fitting prosthesis. ${ }^{40}$

\section{G. Methodology to Measure Accuracy}

Accuracy is defined by the ISO 5725 standard that uses two terms "Trueness" and "Precision" to describe the accuracy of a measurement method. Trueness refers to the closeness of agreement between the arithmetic mean of a large number of test results and the true or accepted reference value. Precision refers to the closeness of 
agreement between test results. Less precision is reflected by a larger standard deviation. $^{23}$

To accurately assess the distortions in the digital impressions, a method with the least assumed error must be used to obtain the reference values. ${ }^{41}$ Previous studies have used gauges like vernier calipers to coordinate measuring systems like contact digitizers and optical scanners that conform to the ISO 10360 standard for accuracy for CMM systems and may boast of precision up to $0.1 \mu \mathrm{m}$. $^{42,43,44}$ Since the laboratory optical scanners used in dentistry have shown high accuracy values, a number of previous studies have used it as an established method to generate a reference mesh to compare the accuracy of the 3D meshes obtained using intraoral scanners. ${ }^{45,46,47}$

Methods that involve comparison of 3D meshes for inspection and analysis utilize industrial 3D metrology software that is used in industries like the aerospace and automobile industries to manufacture precise parts, measure part tolerance and ensure dimensional quality.

The methodology used in the 3D metrology software to digitally measure distortion parameters varies depending on the study design for example the number of implants, angulation of implants or the scan body geometry and the parameters being investigated like the positional deviation, angular deviation or the inter implant distance. ${ }^{7,48,49,50}$ Some of these methodologies specifically investigating the accuracy of digital implant impressions has been established in previous studies. ${ }^{51,52}$

A recent systematic review evaluated the assessment methods to measure implant impression accuracy. They reported the assessment of linear distortion and angular distortions or 3D surface deviations between the reference and test models to be the most frequent parameters tested. Measuring the amount of 3D displacement of the center points of the implant or the scan body, assessing the change in linear 
distance between the two center points, measuring the distance between 2 reference points on the implant body and calculating the closest distance between the long axes of implants being the most commonly used methods to measure linear deviation. Angular distortion can be classified as a rotation of the implant along the long axis and a translational rotation of the implant that can be measured as an angular difference between the implant axis with the reference axis. Additional methods included measuring the marginal discrepancy parameter between the abutments and implant supported framework and strain of the framework when seated on the test models ${ }^{53,41}$

\section{H. Factors Influencing Accuracy}

The accuracy of digital impressions in implant prosthodontics depends on a large number of factors and can be influenced by their interaction.

Factors related to the IOS:

- In terms of technology, it's built and ergonomics can influence operator handling, learning and experience. Though operator experience may not influence accuracy. ${ }^{54}$

- Surface matting using titanium dioxide powder and the thickness of the applied powder. Significant differences were found between the coating and non-coating scanners but the excess coating was found to not have any effect. $^{55}$

- The scanning protocol where the one-step scanning protocol seemed beneficial. ${ }^{56,57}$ Mizumoto $\mathrm{R}$ et al evaluated scanning strategies in full arch scans and found splinting the scan bodies with floss lead to greater distance deviation and surface modifications did not make a difference. ${ }^{47}$

- The calibration of the device. 
Patient-related factors:

- The state of edentulism, the location and extent. Digital impressions show lower precision in complete arch scans with multiple implants. Clinically acceptable precision is noted with digital impressions for short-span FDPs on two implants. ${ }^{58,59,60,61}$

- The presence of teeth acts as reference points for the scanner to stitch the images accurately but tooth position and anatomic discrepancies like the presence of crowding, rotation, supra-eruption, steep inclines can impede the data capture creating voids in the scan. ${ }^{45}$

- Surface characteristics like roughness, translucency contributed by the presence of different restorative materials can increase surface reflectivity although the scanning inaccuracies were found to be within acceptable limits. $^{62}$

- A high degree of humidity due to exhaled air, presence of saliva increases the reflective surfaces affecting the accuracy and drying the surface is recommended. ${ }^{18,62,63}$

- Motion artifacts due to patient movement. Newer scanners have introduced a motion detection technology to minimize errors. ${ }^{18}$

Implant and scan body related factors:

- Reducing inter-implant distance reduced the global linear distortions in the impression. ${ }^{64,57}$

- The accuracy for digital impressions was the same for angulated and parallel implants, unlike conventional impressions that showed a greater accuracy with parallel than angulated implants. With angulated implants, no difference was noted between digital and conventional impressions. ${ }^{54,65,66}$

- Implant depth influenced the amount of visible scan body. ${ }^{48,37}$ 
- Implant connection. ${ }^{67}$

- Scan body position, geometry ${ }^{49,51,47}$

- Material composition 68

- Inter-scan body distance affected the precision of the scan. ${ }^{51}$

- The influence of detachment and repositioning of the scan body was not significant. ${ }^{51}$

- Scan body fit discrepancy was found to be higher in the original implants compared to the lab analogs. ${ }^{7}$

Environment-related factors:

- Ambient light influences the scanning time and accuracy especially in complete arch scans, keeping the ceiling light on and using a blue light scanner was found to improve the scanning accuracy, also avoiding. The chair light may have a negative effect on the accuracy. ${ }^{69,70,71}$

\section{Statement and Significance of the Problem}

A number of factors govern the optimal planning and ultimate positioning of the implant. Implants may need to be placed at an increased depth due to restorative, esthetic or surgical reasons. Restorative space dependent on the planned prosthesis, location of the restoration for example a single implant in the esthetic zone may need to be positioned at an increased depth to account for an optimal emergence profile, morphology and volume of remaining bone in the edentulous site, and unexpected surgical complications may require deviation from the planned implant position.

The IOS used to restore the implant is a non-contact scanner that relies on optical principles to 3D map the scan body. Unlike a direct impression coping that can be 
customized to increase the length in cases of greater implant depth ${ }^{72}$ the length of an intraoral scan body cannot be customized due to oral space constraints and to allow the alignment of the scan body CAD file to the scan body impression in the dental CAD software. The consensus on the influence of implant depth on the accuracy of digital impressions is ambiguous.

The fabrication of an implant prosthesis is an interlinked process whether a conventional or digital workflow is used. Errors that occur in every step beginning with the impression will propagate and have a cumulative effect on the fit of the prosthesis. Identifying the source of error and factors influencing it will help minimize the misfit of the final prosthesis and prevent complications associated with misfit that can prove to be catastrophic.

\section{Purpose}

The purpose of this in vitro study is to investigate the accuracy of digital impressions using an intraoral scanner at varying implant depths by correspondingly adjusting the visibility of the scan body.

\section{Hypothesis and Null Hypothesis}

\section{The Hypothesis}

There will be a significant difference in the accuracy of digital impressions obtained using an intraoral scanner at varying implant depths and corresponding scan body exposure.

\section{The Null hypothesis}


The implant depth and corresponding exposure of the scan body will have no influence on the accuracy of digital impressions obtained using an intraoral scanner.

\section{Assumptions}

1. The implant analog channel in the master model was carefully fabricated to avoid any lateral component of movement of the scan body that would be visible to the naked eye.

2. Soft tissue of $3 \mathrm{~mm}$ thickness measured from the facial and lingual margins of the implant analog channel apically.

3. Type 4 gypsum was used for the fabrication of the master model due to its matte finish that reduced any reflective surfaces and was assumed to be CAD compatible. 4. The implant depth evaluation for each group was assumed to be repeatable at the same level from the buccal view.

5. A uniform controlled environment: The entire study was performed in a closed room under the same lighting conditions on one day to prevent time lapse between the data collection and reduce environmental factors affecting the accuracy of the scans.

\section{Limitations}

1. Sample size: A sample size limited to 15 scans per group

2. Invitro study: Results of this study should be extrapolated for clinical application with caution.

3. Accuracy of laboratory scanner: The manufacturer reported accuracy of the laboratory scanner used to generate the reference scans was $+/-15 \mu \mathrm{m}^{73}$

4. Replication of intraoral conditions was not attempted. 
5. Use of a single intraoral scanner

6. Use of a single intraoral scan body

7. The entire master model was made of gypsum. A gingival silicon moulage was not used to mimic gingival tissue to maintain a uniform scanning surface.

8. Limited experience with the type of intraoral scanner used.

9. Limited experience with 3D metrology software.

10. Non-standardized method to evaluate accuracy.

\section{Delimitations}

The digital impression accuracy studied was limited to the following factors:

1. A partially dentate quadrant

2. Maxillary arch

3. Single posterior edentulous span

4. Single internal connection implant

5. Single intraoral scanner

6. Zero degrees implant angulation

7. No comparison with conventional impressions

8. Single scan body tested

9. Master model limited to a single material

\section{MATERIALS AND METHODS}

\section{Master Model Fabrication}

A single master model was fabricated that allowed the positioning of an implant analog at varying depths within it. An existing conventional open tray vinylpolysiloxane impression (3M $\mathrm{M}^{\mathrm{TM}}$ Imprint ${ }^{\mathrm{TM}} 3$ VPS Impression Material, 
Straumann RC impression post open tray, Figure 8) of a partially edentulous maxillary arch recording the position of an implant placed in the region of the missing left first molar was used to fabricate the master model.

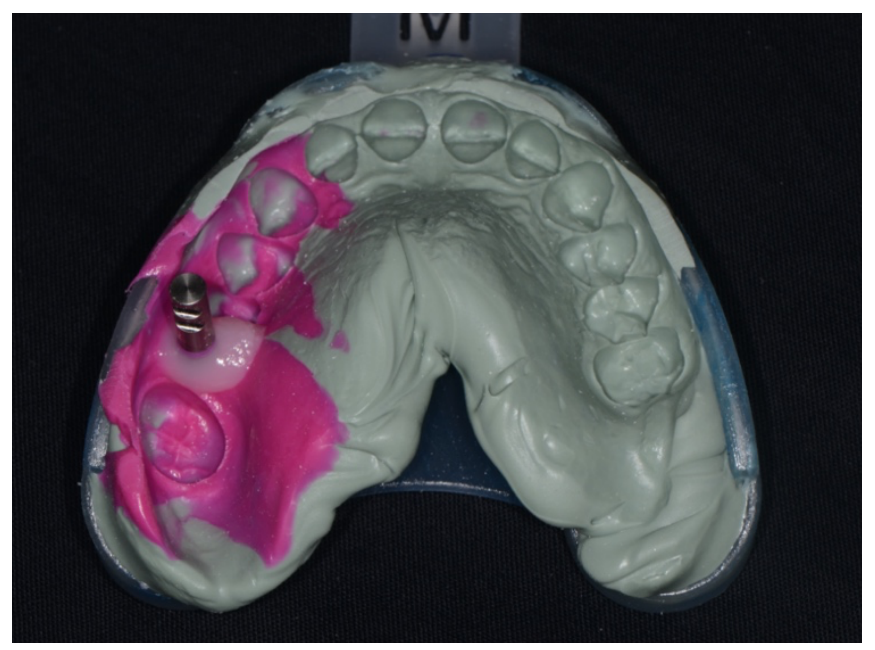

Figure 8: Master Impression of the partially edentulous maxillary arch.

An implant analog (Straumann RC Bone Level Implant Analog-L-12mm, Ti) was modified to block the manufactured undercuts on its body with baseplate wax (Modern Materials Shur wax X-Hard, Kulzer, Inc. Figure 9).

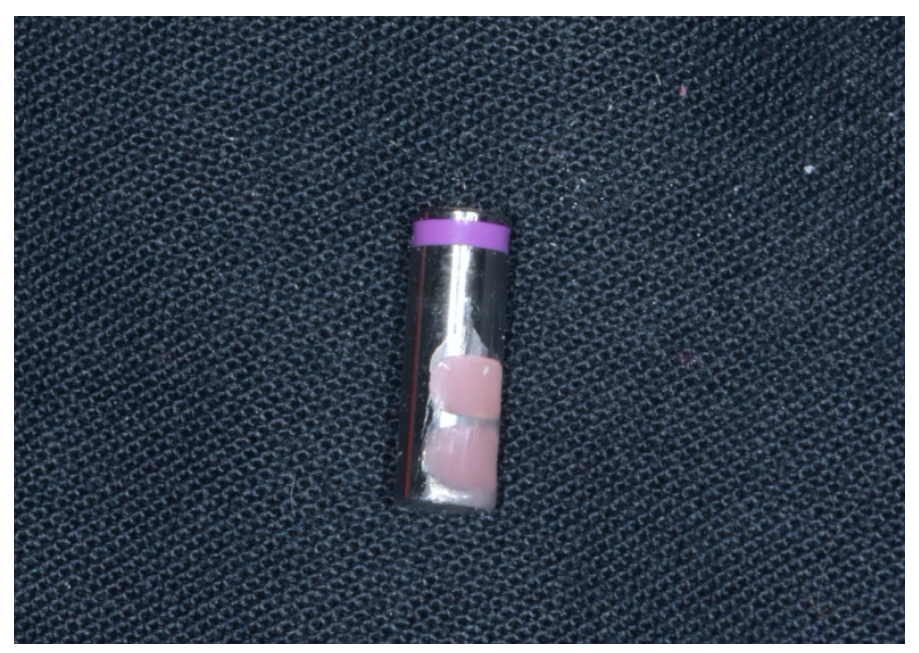

Figure 9: Modified Implant analog 
The implant analog was then connected to the open tray impression post and finger tightened using the manufacturer's driver (Straumann SCS Screwdriver). The left quadrant of the impression was isolated by beading and boxing with square wax ropes (Kulzer, Inc.) and boxing wax (Hygenic). (Figure 10A-B) A thin layer of petroleum jelly was applied to the implant analog to prevent it from getting embedded within the poured stone.
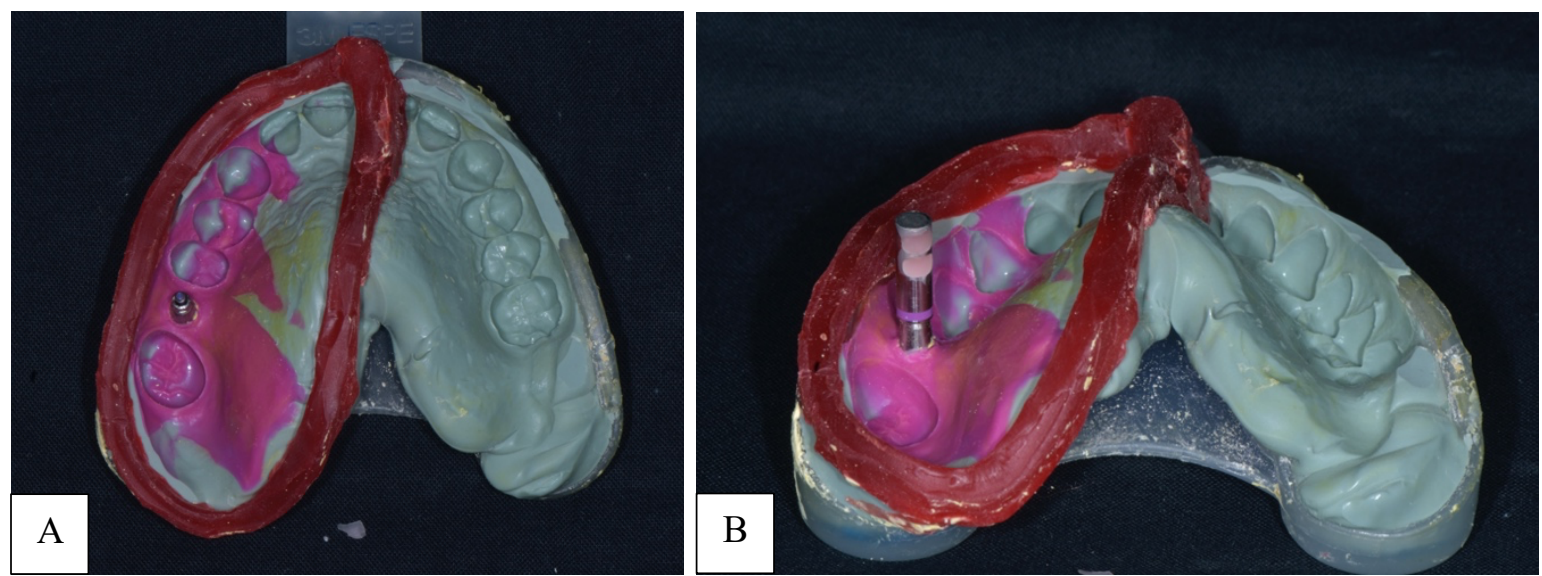

Figure 10: A. Isolation of the left quadrant with beading wax. B. Implant analog in position.

The impression was poured using vacuum mixed Type IV Low-Expansion Die stone and allowed to set for 30 mins beyond the manufacturer's recommended setting time (Silky-Rock ISO Type 4, Whip-Mix Corporation.) The retention screw of the impression coping was unscrewed using the driver and the stone model was then retrieved from the impression. The implant analog was backed out carefully to avoid damaging the model, leaving a channel within the stone model equivalent to its dimensions. The channel was verified to allow vertical movement, but no lateral movement of the implant analog, which facilitated positioning it at varying depths. The facial and lingual margin of the coronal portion of the channel were set as reference points to mark the soft tissue level and a hypothetical plane at a $3 \mathrm{~mm}$ 
depth was considered to be at bone level assuming a $3 \mathrm{~mm}$ soft tissue thickness to mimic anatomic conditions.

To secure the implant analog at the pre-planned depths using a VPS putty jig, adequate space had to be created for the putty jig. Baseplate wax (Figure 11A) was molded into a cube and attached to the undersurface of the stone model in the region of the implant analog and the model was embedded into a Type III Lowexpansion gypsum stone patty to fabricate a base (Mounting Stone ISO Type 3, Whip-Mix Corporation. Figure 11B). The base was trimmed using a gypsum model trimmer (Whip-mix Corporation) to dimensions. The baseplate wax cube was removed from the undersurface of the base of the model creating a recess that connected to the implant analog channel. The model was left undisturbed for a minimum of 48 hours as per the manufacturer's recommendation to reach maximum compressive strength.
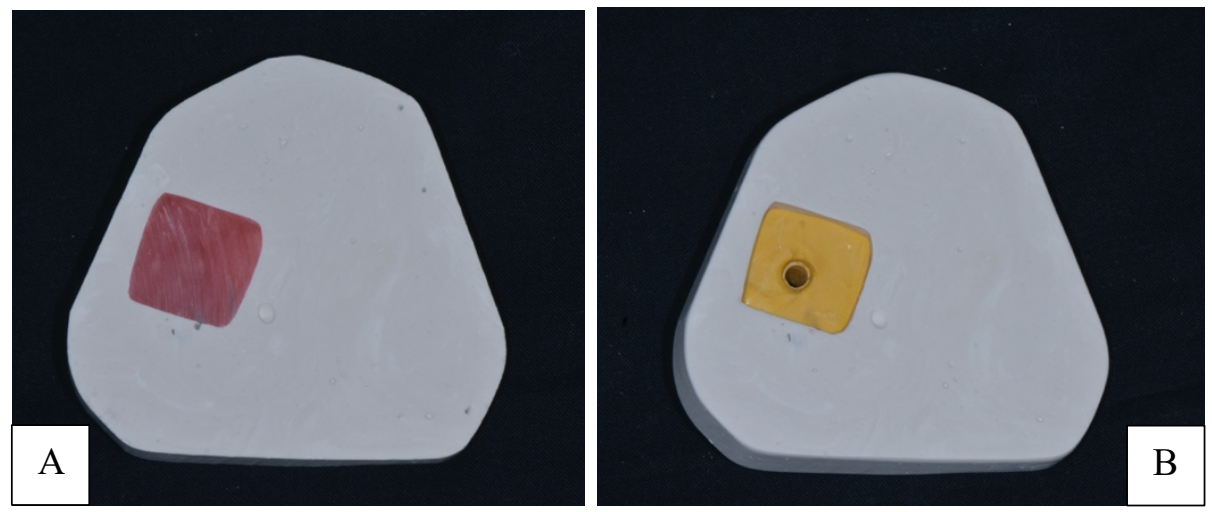

Figure 11: A. Wax cube spacer. B. Recess in the base for VPS putty jig.

A scan body was connected to the implant analog and finger tightened using the screwdriver and positioned in the model with the offset facing buccally (Straumann CARES ${ }^{\circledR}$ RC Mono Scanbody $\varnothing 4.1 \mathrm{~mm}$, H 10mm, PEEK, TAN). 


\section{Referencing Instrument}

To ensure accurate and repeatable positioning of the master model and the scan body-implant analog complex at the planned depths, a dental surveyor was used (Ney ${ }^{\circledR}$ Surveyor, DENTSPLY International, Inc.).

The length of the flat portion of the straight wax knife accessory tool of the surveyor measured $15 \mathrm{~mm}$. A plastic scale (DENTSPLY International, Inc.) with millimeter markings was carefully trimmed to create a $15 \mathrm{~mm}$ length section. This section was then affixed onto the wax knife to create a customized reference scale. (Figure 12.A)

The master model was mounted onto the dental surveyor's table and oriented three-dimensionally such that the reference scale faced buccally and was lying parallel, contacting the model $1 \mathrm{~mm}$ lingual to the lingual margin. (Figure 12.B) The tilt-top model clamp, the locking screw of the tilt-top pivot and the vertical spindle tightening screw was fastened to lock the position of the master model in relation to the reference scale. The surveyor table position on the horizontal surveyor base was fixed using square wax ropes. (Figure 12.C) Three reference markers were placed on the surveyor table model holder that extended onto the base of the master model as tripodal markers for repeatable positioning of the model on the surveyor table. (Figure 12.D-E) At the junction of the vertical spindle and the cross arm, another set of reference marks were placed to ensure the repeatable positioning of the reference scale in relation to the model. (Figure 12.F) 

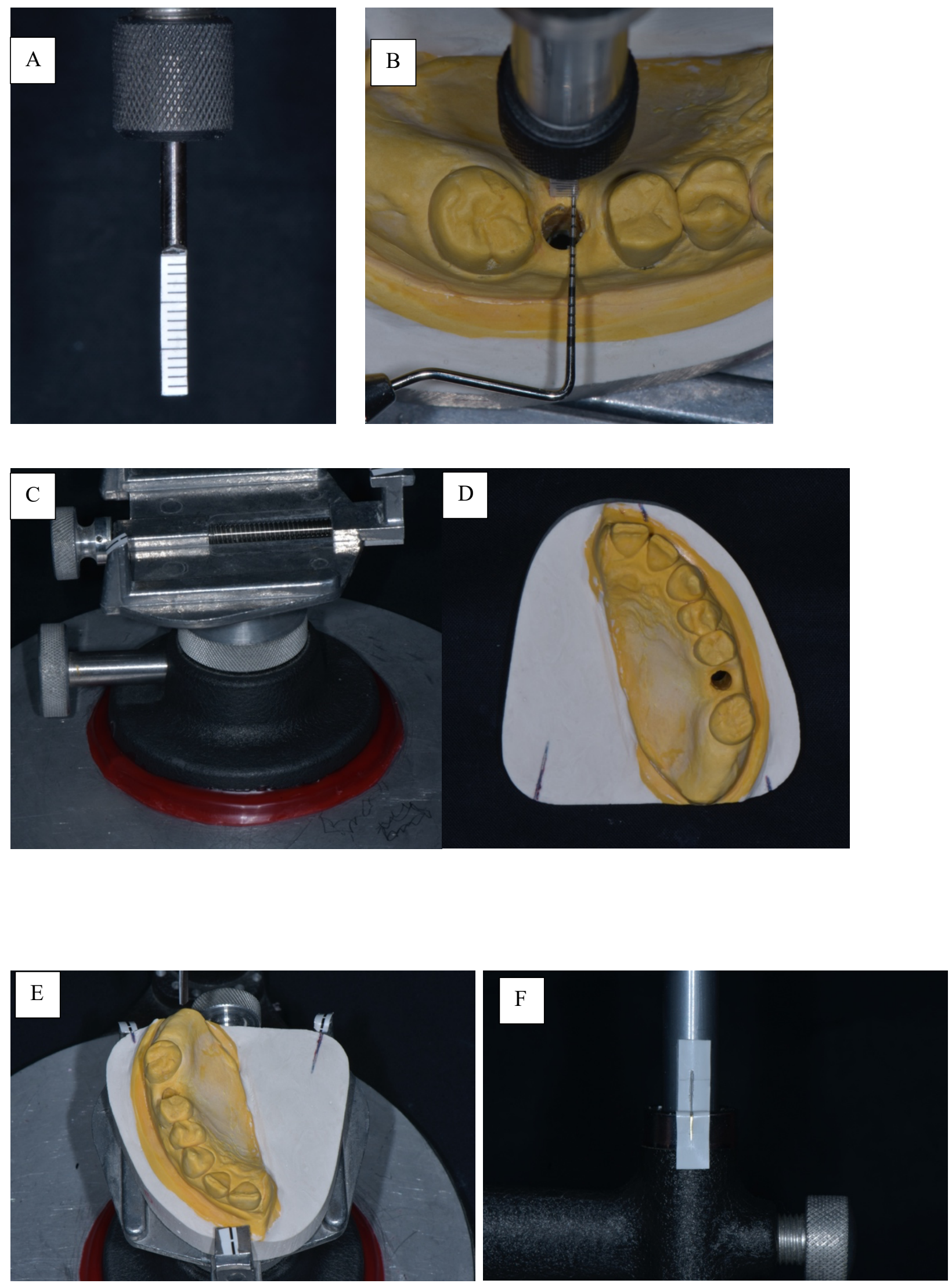

$-26-$ 
Figure 12: A. Customised reference scale. B. Point of contact of reference scale on the model. C. Surveyor table fixed to the horizontal base. D. Master Model with reference markers. E. Corresponding reference markers on the surveyor table holder. F. Reference markers on the vertical spindle.

\section{Study Design}

Four groups were created based on the implant depth and the corresponding level of visibility of the scan body with the offset oriented buccally as per the manufacturer's instructions for the scanning protocol. The scan body when connected to the implant analog measured $9 \mathrm{~mm}$ in length from the coronal flat surface to the implant analog platform. To position the scan body accurately at varying depths, the level of visibility of the scan body was measured against the reference scale using the coronal flat surface as the reference plane from the buccal view.

2mm Group: Complete visibility of the offset of the scan body from the buccal view measuring $2 \mathrm{~mm}$ on the reference scale and the implant analog platform positioned $7 \mathrm{~mm}$ subgingival.

$3 \mathrm{~mm}$ Group: Partial visibility of the scan body from the buccal view measuring $3 \mathrm{~mm}$ on the reference scale with the implant analog platform positioned $6 \mathrm{~mm}$ subgingival.

$6 \mathrm{~mm}$ Group: Partial visibility of the scan body from the buccal view measuring $6 \mathrm{~mm}$ on the reference scale the implant analog platform positioned at $3 \mathrm{~mm}$ subgingival.

9mm Group: Complete visibility of the scan body from the buccal view measuring $9 \mathrm{~mm}$ on the reference scale and the implant analog platform positioned at $0 \mathrm{~mm}$ equigingival. 
Previous studies were referenced to determine the sample size. Most studies used a sample size of ten scans per group. (Batak B et al 202049, Motel C. et al 202056) A sample size of fifteen scans per group was set in this study.

\section{Scanning Protocol}

Four vinyl polysiloxane putty jigs corresponding to the dimensions of the recess in the base of the master model were fabricated (Panasil ${ }^{\circledR}$ Kettenbach GmbH \& Co. KG, Figure 13).
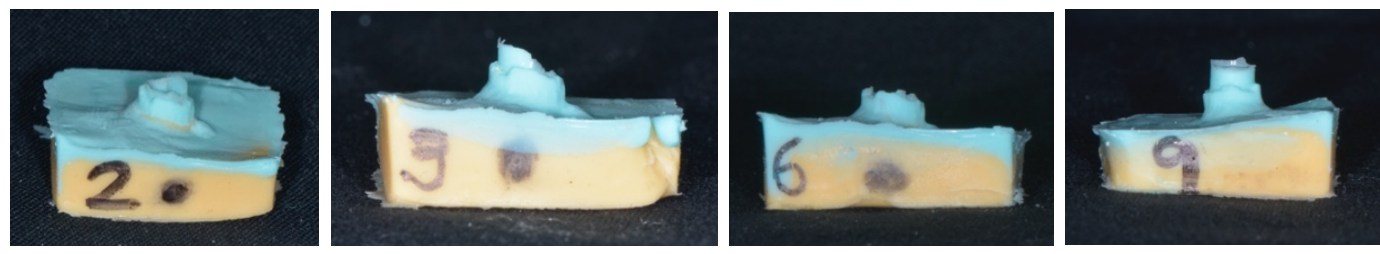

Figure 13: VPS jigs to fix the implant analog at the planned depths.

For the first group, the putty jig was loaded with light body VPS impression material and placed in the recess of the master model (Panasil ${ }^{\circledR}$ Initial Contact Light, Kettenbach GmbH \& Co. KG). The model was oriented to align the reference markers on the surveyor table with those on the model and the reference markers on the vertical spindle were aligned. The scan body-implant analog complex was placed at a depth to correspond to the $2 \mathrm{~mm}$ mark on the reference scale till the impression material sets.

The master model was scanned using a calibrated open system white light optical laboratory scanner (Zfx Scan III, Zfx GmbH. ISO 13485 certification, Figure 15A) with an accuracy of $+/-15 \mu \mathrm{m}$ as per the manufacturer to generate a reference scan that was exported in the STL format.

Fifteen digital impressions were then generated of the master model using a LED (Amber, Blue, Green) optical scanner with an active 3D video technology (CS 
3600, Caresteam Dental LLC., Figure 15B). Manufacturer recommended implant acquisition scanning protocol was followed that consisted of scanning one surface beginning with the occlusal surface of the implant area and then scanning the surrounding teeth on the jaw followed by the lingual surface again starting with the implant area and then scanning the surrounding teeth on the jaw. Finally, the buccal surface was scanned, starting with the implant area and then scanning the surrounding teeth on the jaw. As per the software workflow, the scan was modified by editing the implant area and rescanning to acquire the scan body. A scan was considered complete when no major voids were present. The software enabled exporting the scans in STL format.
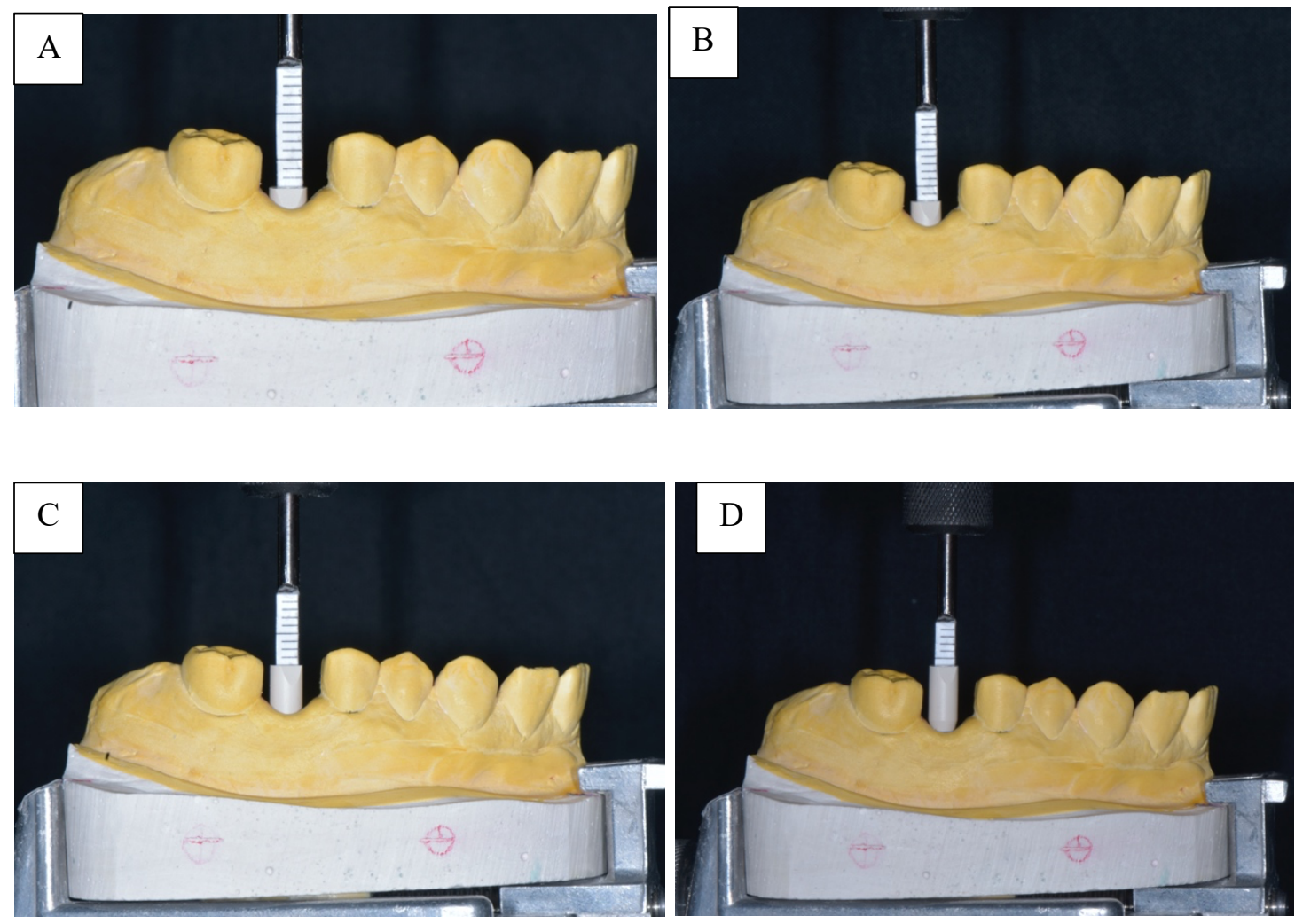

Figure 14: A: Group 2mm implant analog placed 4mm depth subcrestal. B: Group 3mm with implant analog placed $3 \mathrm{~mm}$ subcrestal. C: Group $6 \mathrm{~mm}$ with implant analog placed equicrestal. D: Group 9mm with implant analog placed at soft tissue level. 
The same procedural steps described above were repeated to generate a reference scan and intraoral scans for the $3 \mathrm{~mm}, 6 \mathrm{~mm}$ and $9 \mathrm{~mm}$ groups respectively. (Figure 14 A-D)

A total of four reference scans and 60 intraoral scans were recorded. All scans were exported in STL file format, organized and stored in their respective folders. (Figure 14 C-D) All the intraoral scans were generated in a uniform light, temperature and moisture environment. To eliminate discrepancy associated with the seating and unseating of the scan body and the VPS jig repositioning, the same scan body-implant analog complex was used throughout the study and the VPS jig was left untouched.
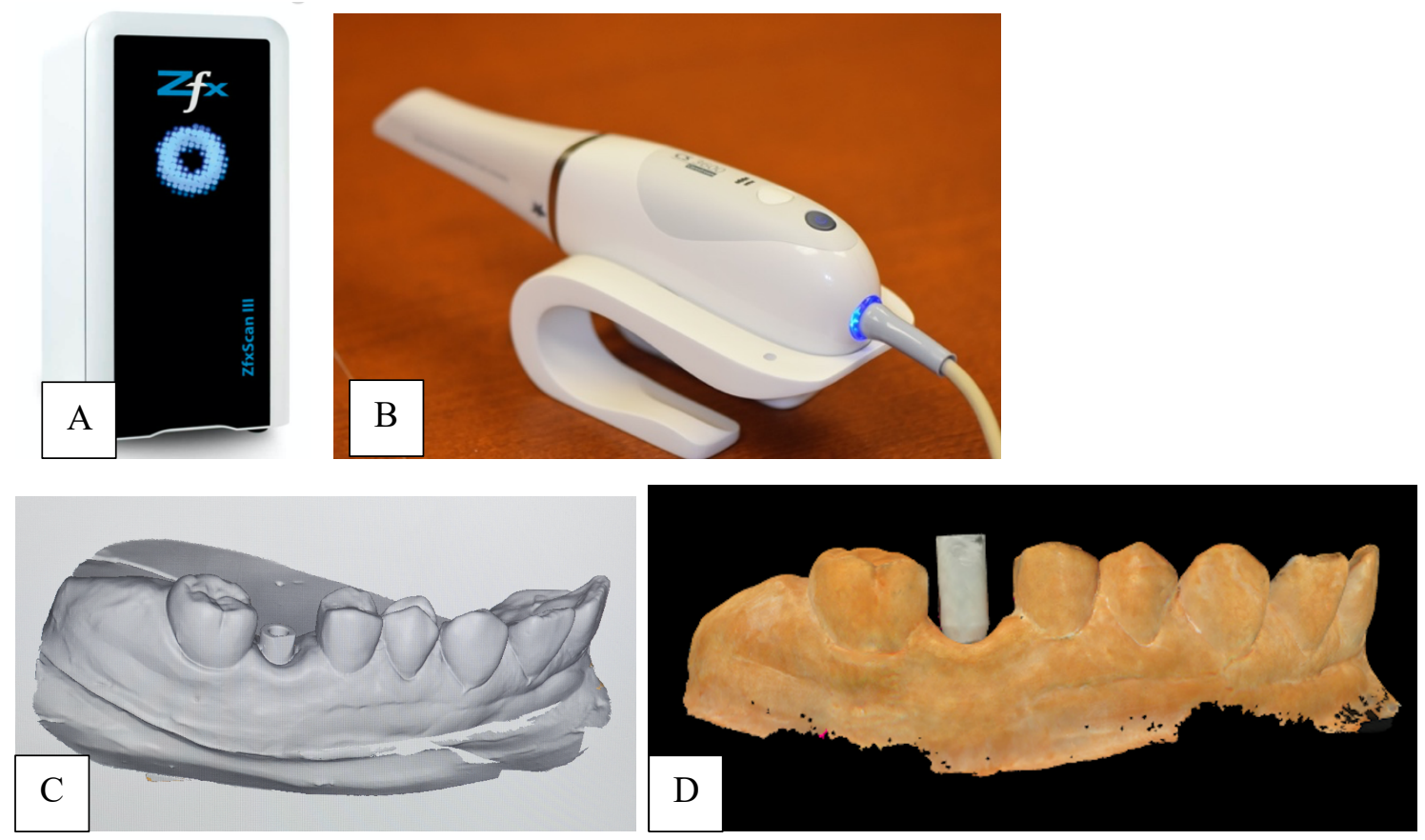

Figure 15: A: Zfx III Laboratory Scanner. B: Carestream CS3600 IOS. C: Reference scan for the $3 \mathrm{~mm}$ group. D: Test scan for the $9 \mathrm{~mm}$ group

\section{Measuring Protocol}


An industrial 3D metrology software, GOM Inspect Suite 2020 (GOM gmbH, ZEISS group) was used to superimpose and compare the test scans with the reference scan of each group.

The reference scan of one group was imported into the software and geometric elements were constructed to create a custom coordinate system. The coordinate system was transformed into the global coordinate system aligning the reference scan to it. The elements are constructed such that the X-axis corresponded to the mesio-distal plane, the $\mathrm{Y}$-axis to the bucco-lingual plane, and the $\mathrm{Z}$-axis to the corono-apical plane. The reference scans of the remaining groups were imported and aligned to the first reference scan to maintain a uniform point of origin and orientation in relation to the global coordinate system. Such alignment was possible since the reference scans of all groups were made from the same master model.

In each test scan comparison, the reference scan was set as the CAD and the test scan as the mesh to enable the software to perform all measurements against the reference data set. (Figure 16)

The superimposition was done using the prealignment function of the software as an initial alignment followed by refining the alignment by using the local best fit function that uses an iterative least square fitting algorithm. The scan body was deselected in the test scan while performing the latter alignment to limit the distribution of the distance errors between the two point clouds to the whole scan except the scan body and obtain accurate deviation values with regards to the scan body. The alignment deviation values were recorded for each scan.

The cylindrical surface and flat top of the scan body in the reference scan were used as the reference data set to construct a nominal cylinder and a plane with its corresponding actual elements on the scan body of the test scan. A point of 
intersection between the cylindrical axis and the plane was constructed and referenced to produce a corresponding point of intersection on the test scan. The overall positional deviation and axis-specific positional deviation between the two points were measured along the $\mathrm{X}, \mathrm{Y}$ and $\mathrm{Z}$ axis. The angular deviation between the nominal and the actual cylindrical axes was measured that corresponded to the angular deviation between the scan body of the reference and test scan using a two directions angle function. (Figure 17-18) The recorded data was organized and compiled in a comma separated values file format (.csv) for statistical analysis.

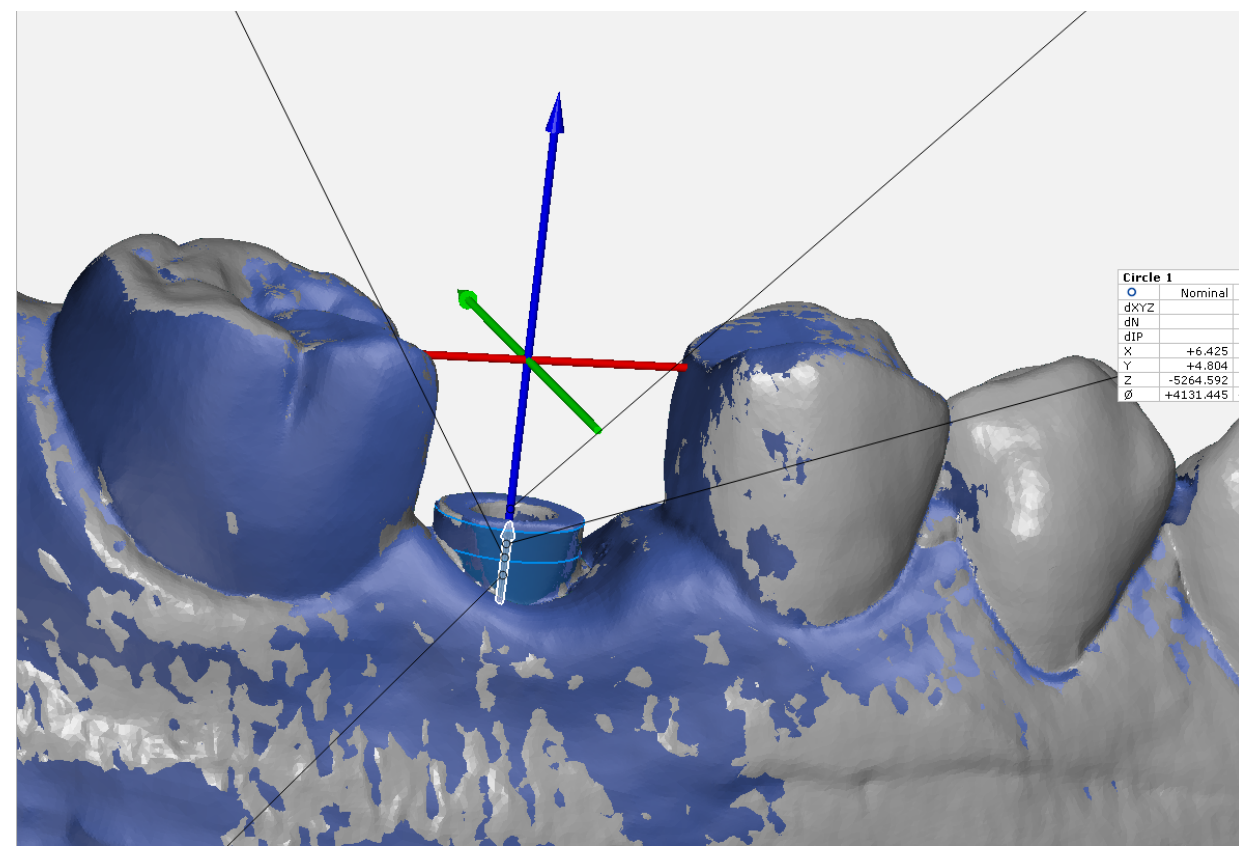

Figure 16. 2mm group: The reference model was oriented to the local coordinate system. Best fit alignment was performed of the reference and test scan. Nominal elements consisting of a cylinder, plane and an intersection point were constructed to measure positional and angular deviation. 


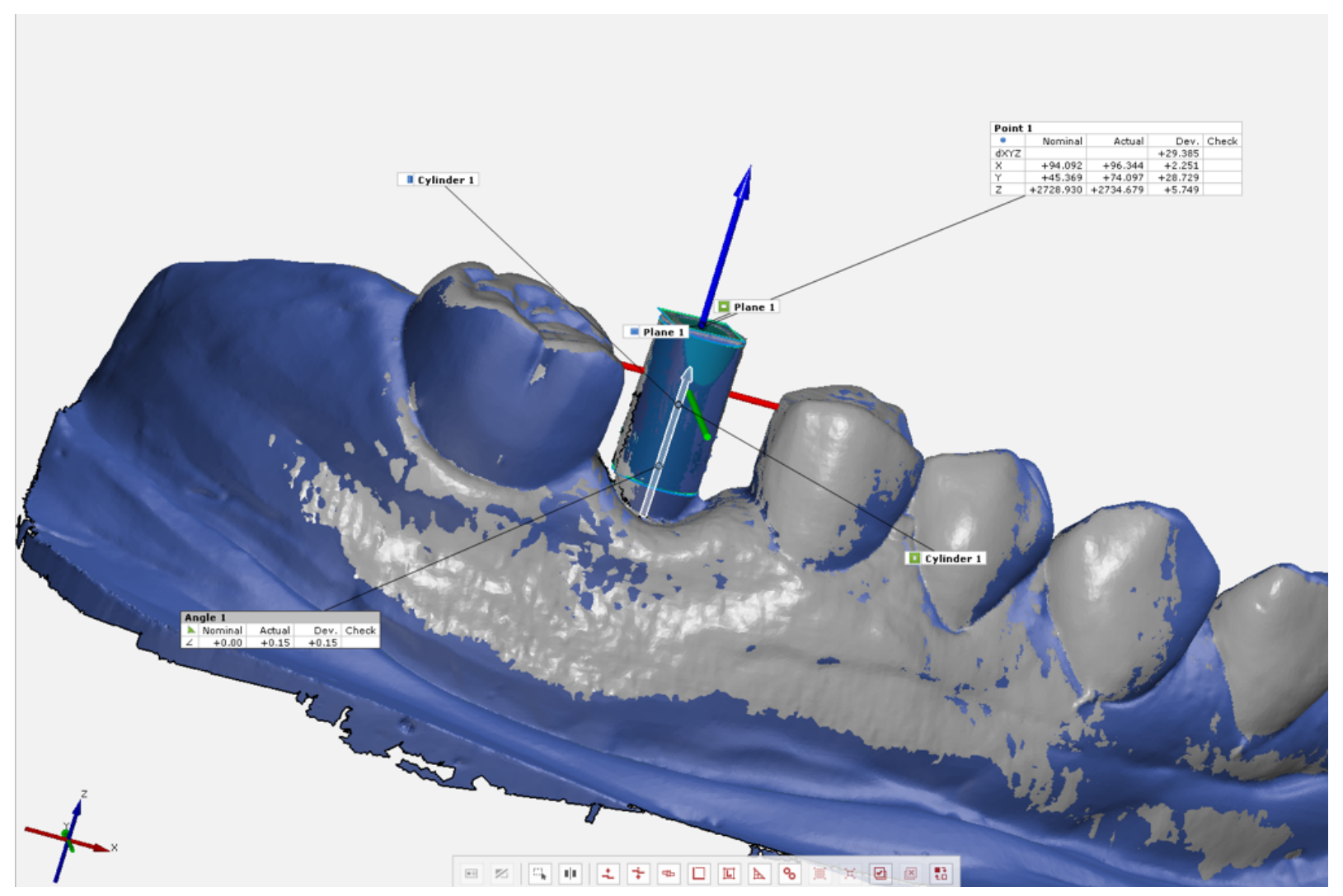

Figure 17. 9mm group: The reference model was oriented to the same local coordinate system. Best fit alignment was performed of the reference and test scan. Nominal elements consisting of a cylinder, plane and an intersection point were constructed to measure positional and angular deviation. 

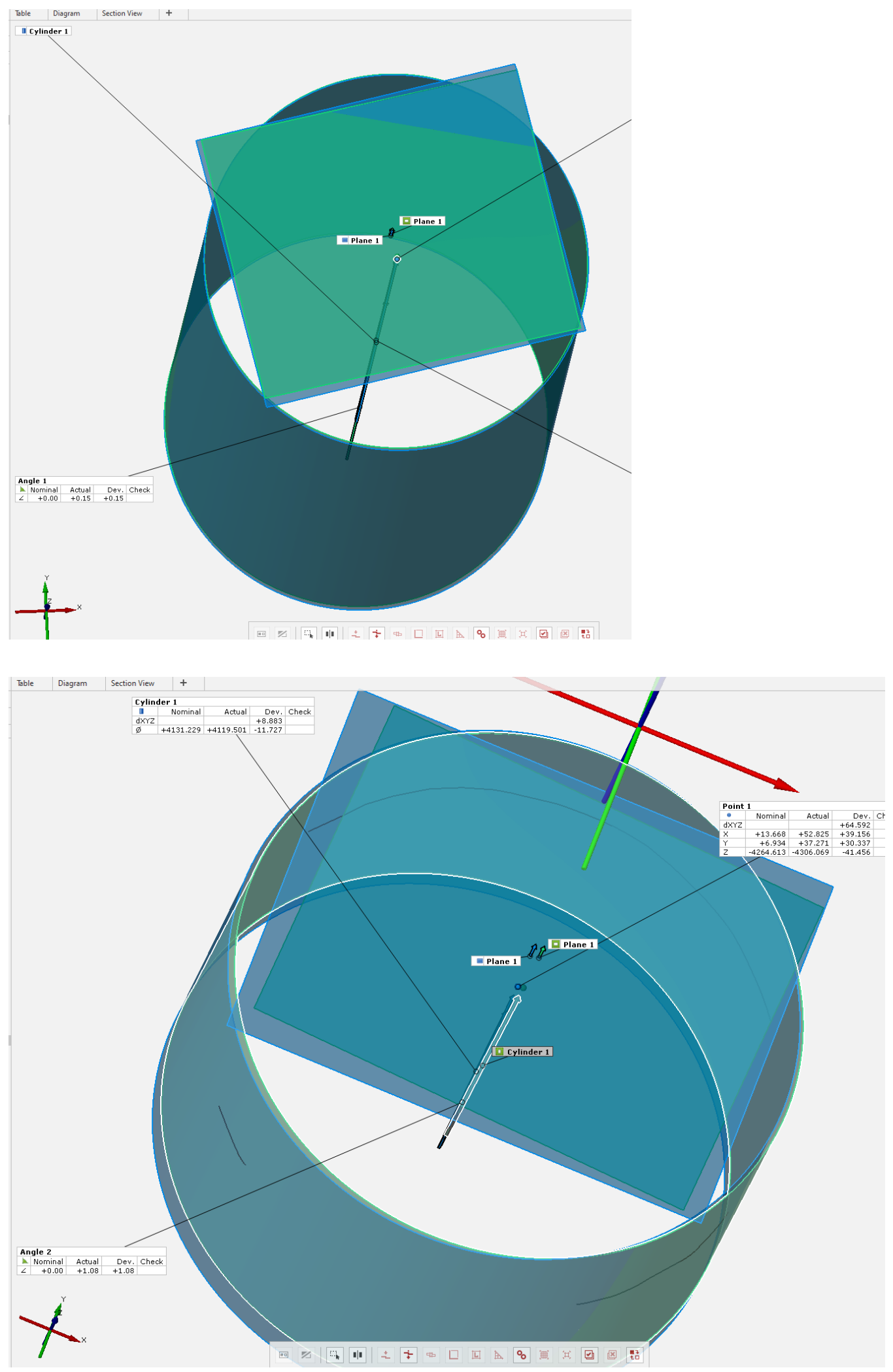

Figure 18. Zoomed view of the discrepancy between the constructed nominal elements corresponding to the scan body cylinder of the reference and test scans in the $9 \mathrm{~mm}$ and $3 \mathrm{~mm}$ groups. 


\section{Statistical Analysis}

The data were analyzed using statistical analysis software. Descriptive statistical analysis revealed the data to be normally distributed. The mean, standard deviation and confidence intervals were calculated for each parameter. A one-way analysis of variance was performed to analyze the effect of the implant depth on the overall positional deviation of the scan body (dXYZ), deviations along each axis ie. X, Y and $\mathrm{Z}$ axis and the angular deviation. A pairwise comparison of the groups was performed using the Tukey-Kramer HSD test. Trueness was calculated as the average deviation in each parameter per group in comparison to the reference scans. The heterogeneity of variance within each group was tested to analyze precision.

\section{RESULTS}

The mean, standard deviation, confidence intervals for each parameter are listed in Tables 1-5.

\section{Positional deviation (dXYZ)}

\begin{tabular}{|c|c|c|c|c|c|c|c|c|c|}
\hline \multicolumn{10}{|c|}{ Variability Summary for dXYZ } \\
\hline & Mean & Std Dev & $\begin{array}{r}\text { Std Err } \\
\text { Mean }\end{array}$ & Lower 95\% & Upper 95\% & Minimum & Maximum & Range & Median \\
\hline$d X Y Z$ & 58.0819 & 26.60917 & 3.43523 & 51.20802 & 64.95578 & 5.92 & 122.194 & 116.274 & 56.495 \\
\hline $\operatorname{depth}[2]$ & 77.17547 & 21.5529 & 5.564935 & 65.23987 & 89.11107 & 35.158 & 114.997 & 79.839 & 74.743 \\
\hline $\operatorname{depth}[3]$ & 70.76427 & 26.66122 & 6.883896 & 55.99978 & 85.52876 & 28.146 & 122.194 & 94.048 & 69.736 \\
\hline $\operatorname{depth}[6]$ & 45.97433 & 21.3875 & 5.52223 & 34.13033 & 57.81834 & 15.849 & 102.305 & 86.456 & 45.519 \\
\hline depth[9] & 38.41353 & 14.71963 & 3.800593 & 30.26207 & 46.56499 & 5.92 & 63.568 & 57.648 & 41.681 \\
\hline
\end{tabular}

Table 1: Variability Summary for dXYZ in $\mu m$ (positional deviation) 
The one-way analysis of variance of the groups for the $\mathrm{dXYZ}$ parameter was statistically significant $(\mathrm{P}<0.0001)$. The least positional deviation was noted with the $9 \mathrm{~mm}$ group at $38.41 \mu \mathrm{m}(95 \% \mathrm{CI} 30.26 ; 46.56)$ and it increased with increased implant depth with the greatest deviation with the $2 \mathrm{~mm}$ group at $77.17 \mu \mathrm{m}(95 \% \mathrm{CI}$ $65.23 ; 89.11)$. According to the Tukey-Kramer pairwise comparison, there was a significant difference in deviation between the 2-6 $(\mathrm{P}<0.0011), 3-9(\mathrm{P}<0.0007)$ and 3-6mm $(\mathrm{P}<0.0133)$ groups with a statistically highly significant difference noted between the $2-9 \mathrm{~mm}$ group at $38.76 \mu \mathrm{m}(\mathrm{P}<0.0001)$. The difference in $\mathrm{dXYZ}$ values between the $2-3 \mathrm{~mm}(\mathrm{P}<0.84)$ groups and 6-9mm $(\mathrm{P}<0.77)$ groups were not statistically significant.

\section{Angular deviation (d $\theta)$}

\begin{tabular}{|c|c|c|c|c|c|c|c|c|c|}
\hline \multicolumn{10}{|c|}{ Variability Summary for angle } \\
\hline & Mean & Std Dev & $\begin{array}{r}\text { Std Err } \\
\text { Mean }\end{array}$ & Lower 95\% & Upper 95\% & Minimum & Maximum & Range & Median \\
\hline angle & 0.436667 & 0.347654 & 0.044882 & 0.346858 & 0.526475 & 0.03 & 1.32 & 1.29 & 0.33 \\
\hline $\operatorname{depth}[2]$ & 0.842667 & 0.339105 & 0.087557 & 0.654876 & 1.030457 & 0.19 & 1.32 & 1.13 & 0.84 \\
\hline depth[3] & 0.472 & 0.2682 & 0.069249 & 0.323476 & 0.620524 & 0.14 & 1.32 & 1.18 & 0.43 \\
\hline depth[6] & 0.261333 & 0.173981 & 0.044922 & 0.164986 & 0.357681 & 0.03 & 0.64 & 0.61 & 0.22 \\
\hline depth[9] & 0.170667 & 0.073918 & 0.019085 & 0.129732 & 0.211601 & 0.05 & 0.35 & 0.3 & 0.17 \\
\hline
\end{tabular}

Table 2:Variability Summary for $d \theta$ in degrees (angular deviation)

The one-way analysis of variance of the groups for the $d \theta$ parameter was statistically significant $(\mathrm{P}<0.0001)$. The least angular deviation of $0.17^{\circ}(95 \% \mathrm{CI}$ $0.12 ; 0.21)$ was noted with the $9 \mathrm{~mm}$ group with an increase in deviation as the implant depth increased with the greatest angular deviation of $0.84^{\circ}(95 \%$ $0.65 ; 1.03)$ was noted with the $2 \mathrm{~mm}$ group. According to the Tukey-Kramer pairwise comparison, there was a significant difference in deviation in the mean $\mathrm{d} \theta$ between the $2-3 \mathrm{~mm}(\mathrm{P}=0.0004)$, and $3-9(\mathrm{P}=0.005)$ groups at $0.37^{\circ}$ and $0.30^{\circ}$ 
and a statistically highly significant difference was noted between the 2-9 ( $\mathrm{P}<0.0001), 2-6(\mathrm{P}<0.0001)$, at $0.67^{\circ}$ and $0.58^{\circ}$ respectively. The pairwise comparison between the $3-6(\mathrm{P}=0.08)$ and $6-9 \mathrm{~mm}(\mathrm{P}=0.071)$ groups was not statistically significant.

No statistically significant difference was noted in the 6-9mm group for the positional and angular deviation parameters.

\section{Deviation along mesio-distal direction ie. along the $X$-axis (dX)}

\begin{tabular}{|c|c|c|c|c|c|c|c|c|c|}
\hline \multicolumn{10}{|c|}{ Variability Summary for $\mathrm{dX}$} \\
\hline & Mean & Std Dev & $\begin{array}{r}\text { Std Err } \\
\text { Mean }\end{array}$ & Lower 95\% & Upper 95\% & Minimum & Maximum & Range & Median \\
\hline$d x$ & 3.89805 & 22.99171 & 2.968217 & -2.04134 & 9.837438 & -57.606 & 52.144 & 109.75 & 4.2365 \\
\hline depth[2] & 10.6386 & 26.13993 & 6.749302 & -3.83721 & 25.11441 & -40.313 & 52.144 & 92.457 & 13.796 \\
\hline depth[3] & -6.35953 & 25.86836 & 6.679182 & -20.685 & 7.965888 & -57.606 & 28.882 & 86.488 & -0.771 \\
\hline $\operatorname{depth}[6]$ & -4.71767 & 13.19342 & 3.406526 & -12.0239 & 2.588605 & -25.46 & 14.944 & 40.404 & -6.14 \\
\hline depth[9] & 16.0308 & 17.39397 & 4.491105 & 6.398338 & 25.66326 & -18.693 & 45.719 & 64.412 & 14.594 \\
\hline
\end{tabular}

Table 3: Variability Summary for $d X$ in $\mu m$ (deviation along the mesio-distal plane)

The variance of the deviation along the $\mathrm{X}$ axis was statistically significant when analyzed by Welch's ANOVA test $(\mathrm{P}=0.0045)$. The mean $\mathrm{dX}$ values for the $2 \mathrm{~mm}$, $3 \mathrm{~mm}, 6 \mathrm{~mm}$ and $9 \mathrm{~mm}$ groups were $10.63 \mu \mathrm{m},-6.36 \mu \mathrm{m},-4.71 \mu \mathrm{m}$ and $16.03 \mu \mathrm{m}$ respectively with the negative value indicating a distal inclination and vice versa. The Tukey-Kramer pairwise comparison revealed a statistically significant difference in deviation between the $3-9 \mathrm{~mm}(\mathrm{P}=0.02)$ and $6-9 \mathrm{~mm}$ group $(\mathrm{P}=0.04)$ at 22.39 and $20.74 \mu \mathrm{m}$ respectively. 


\section{Deviation along bucco-lingual direction ie. along the Y-axis (dY)}

\begin{tabular}{|c|c|c|c|c|c|c|c|c|c|}
\hline \multicolumn{10}{|c|}{ Variability Summary for $d Y$} \\
\hline & & & Std Err & & & & & & \\
\hline & Mean & Std Dev & Mean & Lower $95 \%$ & Upper 95\% & Minimum & Maximum & Range & Median \\
\hline dY & 3.631233 & 38.6956 & 4.99558 & -6.3649 & 13.62737 & -87.829 & 88.956 & 176.785 & 11.378 \\
\hline $\operatorname{depth}[2]$ & -5.0902 & 46.8055 & 12.08513 & -31.0102 & 20.82982 & -80.848 & 55.92 & 136.768 & -7.153 \\
\hline depth[3] & -5.08253 & 41.59746 & 10.74042 & -28.1184 & 17.95337 & -87.829 & 46.751 & 134.58 & 5.808 \\
\hline $\operatorname{depth}[6]$ & 11.67973 & 40.2997 & 10.40534 & -10.6375 & 33.99697 & -57.175 & 88.956 & 146.131 & 11.823 \\
\hline depth[9] & 13.01793 & 20.93868 & 5.406343 & 1.422481 & 24.61339 & -27.861 & 48.123 & 75.984 & 11.898 \\
\hline
\end{tabular}

Table 4: Variability Summary for dY in $\mu m$ (deviation along the bucco-lingual plane)

The variance of the deviation along the $\mathrm{Y}$-axis was not statistically significant when analyzed by the one-way ANOVA test $(\mathrm{P}=0.39)$. The mean $\mathrm{dY}$ values for the $2 \mathrm{~mm}, 3 \mathrm{~mm}, 6 \mathrm{~mm}$ and $9 \mathrm{~mm}$ groups were $-5.09 \mu \mathrm{m},-5.08 \mu \mathrm{m}, 11.68 \mu \mathrm{m}$ and $13.01 \mu \mathrm{m}$ respectively with the negative value indicating a buccal inclination and vice versa. Increased scan body exposure leads to greater lingual inclination but the pairwise comparison of the groups was not statistically significant.

Deviation along coronal-apical direction ie. along the Z-axis (dZ)

\begin{tabular}{|c|c|c|c|c|c|c|c|c|c|}
\hline \multicolumn{10}{|c|}{ Variability Summary for $d Z$} \\
\hline & Mean & Std Dev & $\begin{array}{r}\text { Std Err } \\
\text { Mean }\end{array}$ & Lower $95 \%$ & Upper 95\% & Minimum & Maximum & Range & Median \\
\hline$d Z$ & -33.3326 & 30.88683 & 3.987472 & -41.3115 & -25.3537 & -95.059 & 33.876 & 128.935 & -34.6425 \\
\hline depth[2] & -50.9496 & 32.27426 & 8.333177 & -68.8225 & -33.0767 & -91.555 & 33.876 & 125.431 & -53.94 \\
\hline depth[3] & -52.5001 & 25.54221 & 6.59497 & -66.6449 & -38.3553 & -95.059 & -8.645 & 86.414 & -55.262 \\
\hline depth[6] & -13.456 & 23.66205 & 6.109514 & -26.5596 & -0.3524 & -50.634 & 27.536 & 78.17 & -11.773 \\
\hline depth[9] & -16.4248 & 17.62758 & 4.551422 & -26.1866 & -6.66297 & -43.34 & 5.749 & 49.089 & -10.985 \\
\hline
\end{tabular}

Table 5: Variability Summary for dZ in $\mu m$ (deviation along the corono-apical plane)

The one-way ANOVA revealed a statistically significant difference in the variance of the deviation along the $\mathrm{Z}$-axis $(\mathrm{P}<0.0001)$. The mean $\mathrm{dZ}$ values for the $2 \mathrm{~mm}$, $3 \mathrm{~mm}, 6 \mathrm{~mm}$ and $9 \mathrm{~mm}$ groups were $-50.94 \mu \mathrm{m},-52.5 \mu \mathrm{m},-13.45 \mu \mathrm{m}$ and $-16.42 \mu \mathrm{m}$ 
respectively with the negative value indicating an apical inclination and vice versa. Increased deviation was noted along the apical direction in all groups. The Tukey-Kramer pairwise comparison revealed a statistically significant difference in deviation between the 2-6mm ( $\mathrm{P}=0.0009), 2-9 \mathrm{~mm}(\mathrm{P}=0.0024), 3-$ $6 \mathrm{~mm}(\mathrm{P}=0.0005), 3-9 \mathrm{~mm}(\mathrm{P}=0.0014)$ at $37.49 \mu \mathrm{m}, 34.52 \mu \mathrm{m}, 39.04 \mu \mathrm{m}$ and $36.07 \mu \mathrm{m}$ respectively.

No statistically significant difference was noted in the 6-9 $\mathrm{mm}$ group for the positional and angular deviation parameters.

\section{Best fit Algorithm Error}

The mean overall deviation in merging the test scans to the reference scans was $31.26 \mu \mathrm{m}$. There was no statistical difference in the variance analysis at different depths. $(\mathrm{P}=0.1128)$

\section{Trueness and Precision}

Assuming the deviation value for the reference scan is 0 , the standard error values of the test scan that lie closer to 0 demonstrate higher trueness of the scan. (Table 1-5) The trueness of the scans is highest in the $9 \mathrm{~mm}$ group compared to the other groups and decreases as the implant depth increases and corresponding scan body visibility decreases for the $\mathrm{dXYZ}$ and $\mathrm{d} \theta$ parameter.

The precision is the measure of the repeatability of the scans within the group. The heterogeneity of the variance tested within each group revealed that the $9 \mathrm{~mm}$ group had the lowest standard deviation value of 14.72 for the $\mathrm{dXYZ}$ parameter, lying closest to the lower limit and the $\mathrm{d} \theta$ group standard deviation value of 
0.0739 lying below the lower limit indicating the highest precision compared to the other groups. The $9 \mathrm{~mm}$ group shows greater precision and trueness along the $\mathrm{Y}$ and Z-axis compared to the $\mathrm{X}$-axis. (Table 6-7)
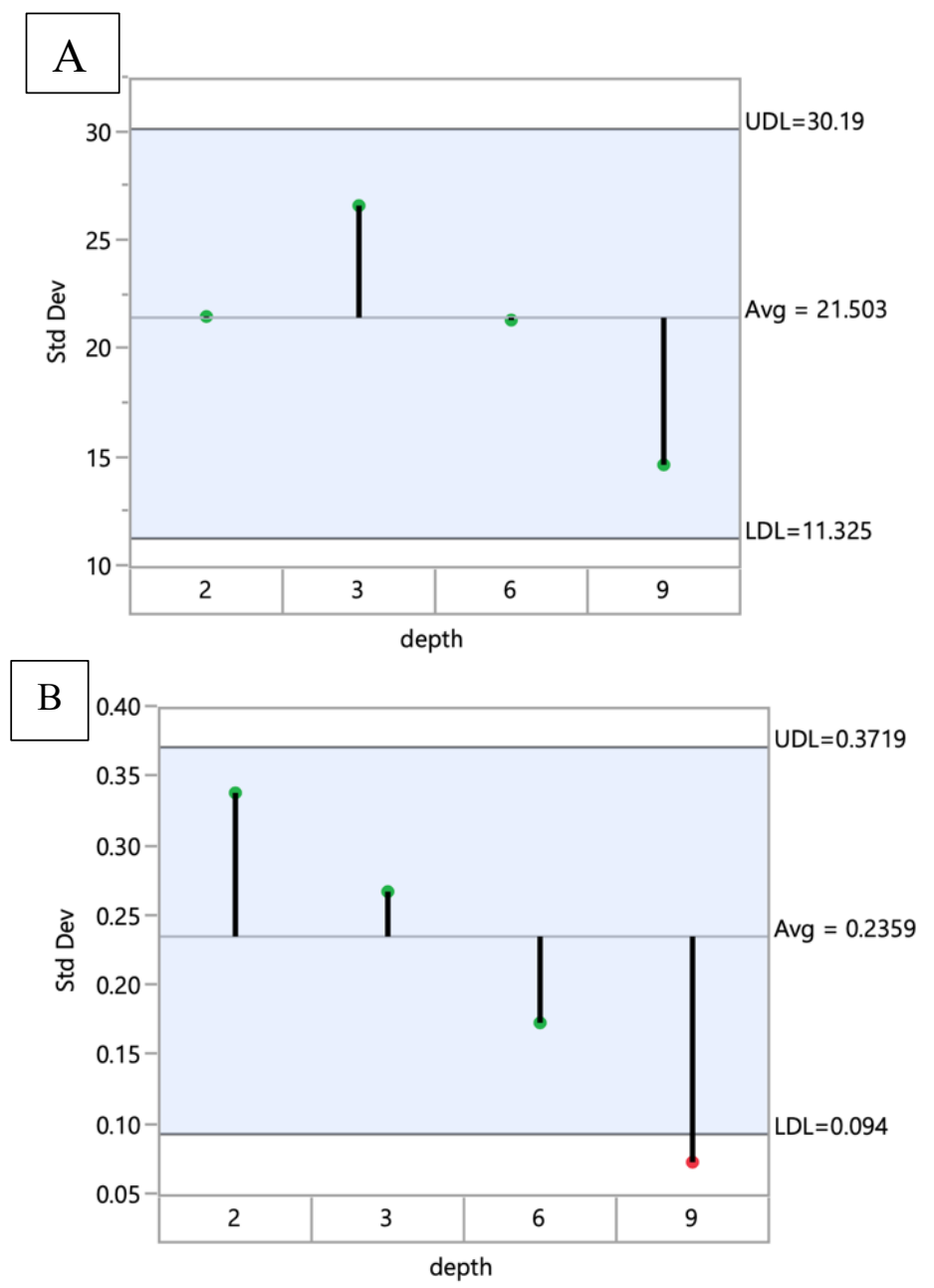

Table 6: A: $d X Y Z$ and $B: d \theta$. Heterogeneity of Variance tested. The standard deviation values lying closer to the lower limit indicate trueness. The $9 \mathrm{~mm}$ group shows the highest trueness compared to the 2 and $3 \mathrm{~mm}$ groups for both parameters. $d \theta$ values in the $9 \mathrm{~mm}$ group are lower than the lower limit indicating values very close to the reference scan. 

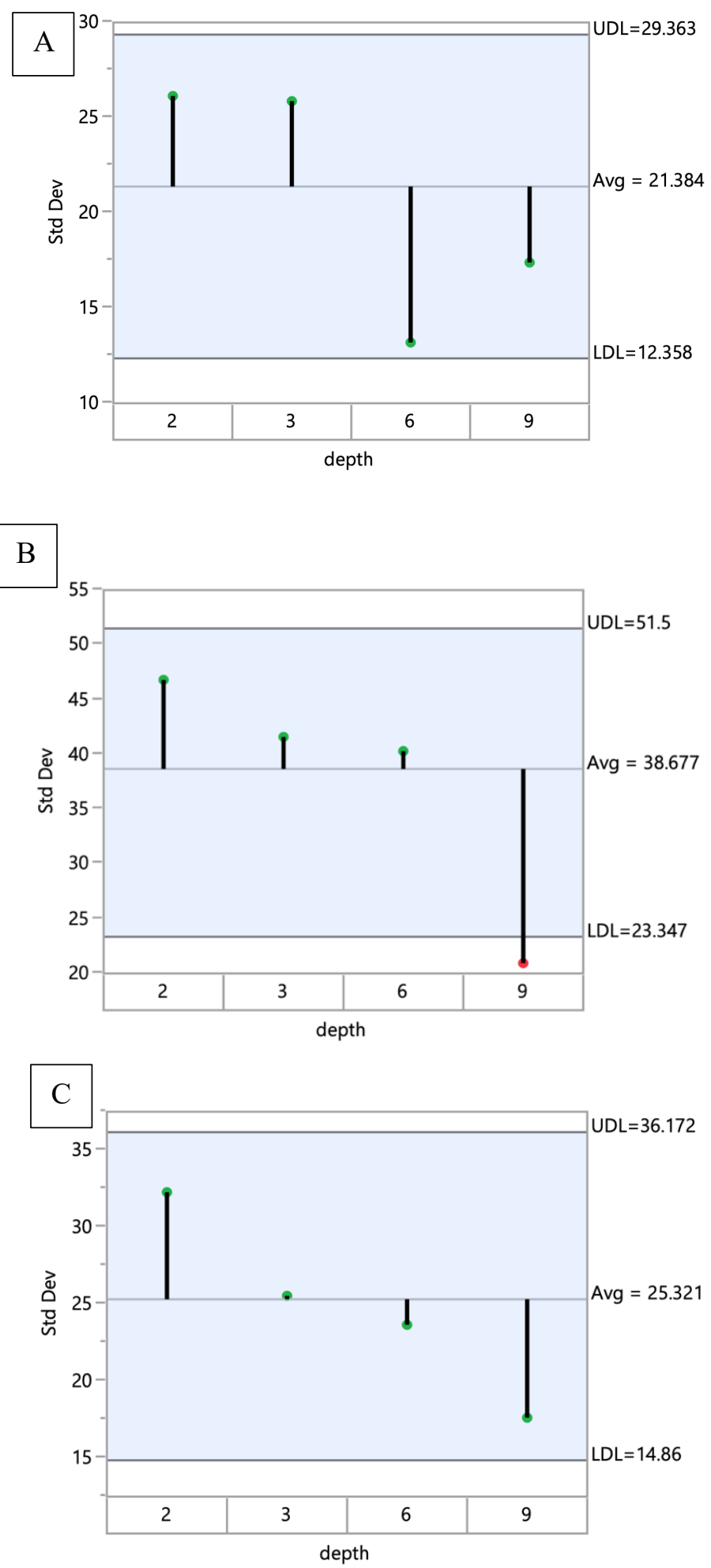

Table 7: A: $d X, B: d Y C: d Z$, Heterogeneity of variance tested. The standard deviation values lying closer to the lower limit indicate trueness. The $9 \mathrm{~mm}$ group shows the highest trueness compared to the other groups, especially along the Y-axis. 


\section{DISCUSSION}

The purpose of this study was to investigate the accuracy of digital impressions using an intraoral scanner at varying implant depths. Based on the results of the study the accuracy of digital impressions decreased with increased implant depth. The implant placed at $0 \mathrm{~mm}$ depth showed the highest accuracy in terms of precision as well as trueness compared to implants placed at a depth of $7 \mathrm{~mm}$ subgingival rejecting the null hypothesis.

Few studies have attempted to investigate the influence of implant depth or the amount of visibility of the scan body on the accuracy of digital impressions. A recent study by Park.S et al, investigated the influence of a defective scan of the scan body on the accuracy of the virtual implant positioning of the analog in a CAD software and concluded that at a deficiency level of $15 \%$ and above, the accuracy of the analog position in the CAD software is adversely affected. ${ }^{74}$ A study by Choi Y. et $\mathrm{al}^{37}$ evaluated the effect of the amount of scan body exposure on the alignment ability of the dental CAD software and subsequently on the implant position. They concluded that the amount of scan body exposure affected the CAD matching process and implant positioning in the software and suggested a software function that selects the portion of the scan body to be aligned. The findings of this study are consistent with the above. The unique geometry of the scan body needs to be recorded and the amount of visible scan body and the scanning protocol needs to be additionally considered while acquiring the scan and allow the CAD software to successfully align a virtual CAD scan body and position the implant analog accurately. The study by Choi et $\mathrm{al}^{37}$, also noted that the inaccuracies increased when the scan body exposure was reduced by more than $1.0 \mathrm{~mm}$. The results of this study showed no significant increase in deviation in the first $3 \mathrm{~mm}$ of implant submergence. Due 
to the difference in the master model used (implant placed in a free end saddle distal to a premolar), the scanning protocol and measuring methodology, no parallels can be drawn with regards to the discrepancy in the depth level at which the deviation is significant.

At a subgingival depth of $3 \mathrm{~mm}$, the implant is relatively positioned at the crest of the bone which is a common scenario for bone level implants. This suggests that the dimensions of the scan body need to be accounted for while planning the implant position especially when it is planned at the crest or further subcrestally. Previous studies by Gimenez B et al using the CEREC Bluecam and Lava COS scanner (3M ESPE, St.Paul, MN) found no difference with implants placed at $0 \mathrm{~mm}, 2$, and $4 \mathrm{~mm}$ subgingivally while in another study using the True Definition scanner (3M ESPE, St.Paul, MN) they found the amount of visible scanbody affected the accuracy of the impression and recommended using longer scanbodies. Another study using the iTero scanner (Cadent Inc. NJ) found greater accuracy with implant placed subgingivally and attributed it to the inaccuracies accumulating in the image stitching process due to the distance of the $0 \mathrm{~mm}$ implant from the first scanned implant. ${ }^{48,54,65,75}$

All the studies mentioned above investigated the influence of implant depth on the accuracy of impressions in a completely edentulous maxillary arch with six implants with conflicting results.

The IOS relies on optical illumination of the surface of the scan body to accurately map it. A significant influence on the deviation values was found in this study as the implants were placed subgingivally in a tooth bound edentulous space. In the present study, only one experimental group (9mm group) had the scan body extend above the occlusal plane. Hence, no conclusions can be drawn, but the interactive effect of the adjacent teeth and reduced visibility of the scan body on the IOS function should be further explored. 
It is difficult to compare the results of the present study with regards to the IOS used due to differences in methodology in the study design and accuracy measurement. Previous studies have validated the accuracy and usage of the laboratory scanner as a reference scanner to assess the accuracy of intraoral scanners. ${ }^{45}$ A recent study by Mangano. F. et al ${ }^{76}$ compared twelve IOS and found the mean error for the CS3600 scanner to be $36.5 \mu \mathrm{m}(95 \%$ CI $29.8 ; 44.6)$ and a study by Imburgia $\mathrm{M}$. et al ${ }^{77}$ compared four intraoral scanners in a partially edentulous model with three implants and found the trueness of the CS3600 scanner to be $45.8 \mu \mathrm{m}( \pm 1.6)$ which is consistent with the results of the present study when the scan body is completely visible at $0 \mathrm{~mm}$ depth ie. $38.41 \mu \mathrm{m}$ (95\% CI $30.26 ; 46.56)$.

Soft tissue thickness can vary due to a number of factors, the inability to customize the soft tissue thickness and the scan body exposure at the planned implant depths beyond $6 \mathrm{~mm}$ may not be representational of the clinically relevant conditions. This in-vitro study tested a single scan body and a single IOS without replicating intraoral conditions. These limitations along with the 3D metrology software mean error of $31.26 \mu \mathrm{m}$ in the alignment process needs to be considered and application of the relevance of the results clinically must be done with caution.

\section{CONCLUSIONS}

Within the limitations of the study, it can be concluded:

1. The accuracy of digital impressions is influenced by the implant depth and the amount of visible scan body. The trueness and precision of the digital impressions is highest when the implant is placed at $0 \mathrm{~mm}$ depth with complete visibility of the scan body and decreases with subgingival implant placement. 
2. No significant increase in accuracies was noted in the first $3 \mathrm{~mm}$ of implant submergence.

\section{FUTURE RESEARCH}

1. Studies need to be conducted to assess the effect of implant depth with multiple implants.

2. The influence of the variation in geometry, dimensions and material composition of scan bodies on the accuracy of impressions and the ability of the CAD software to accurately position the implant analog virtually needs to be investigated.

3. A homogenous methodology of measuring the accuracy of intraoral scanners needs to be defined.

\section{FINANCIAL SUPPORT}

The project was funded by the Department of Restorative Dentistry, West Virginia University School of Dentistry.

\section{REFERENCES}

1. Starcke EN. A historical review of complete denture impression materials. $J$ Am Dent Assoc. 1975;91(5):1037-1041. doi:10.14219/jada.archive.1975.0531

2. Materials D. Revised American Dental Association Specification no. 19 for Non-aqueous, Elastomeric Dental Impression Materials. J Am Dent Assoc. 1977;94(4):733-741. doi:10.14219/jada.archive.1977.0334

3. Donovan TE, Chee WWL. A review of contemporary impression materials 
and techniques. Dent Clin North Am. 2004;48(2):445-470.

doi:10.1016/j.cden.2003.12.014

4. Rekow D. Computer-aided design and manufacturing in dentistry: A review of the state of the art. J Prosthet Dent. 1987;58(4):512-516.

5. Duret F, Blouin JL, Duret B. CAD-CAM in dentistry. J Am Dent Assoc. 1988;117(6):715-720. doi:10.14219/jada.archive.1988.0096

6. Rekow ED. Dental CAD-CAM systems. What is the state of the art? J Am Dent Assoc. 1991;122(12):42-48. doi:10.14219/jada.archive.1991.0205

7. Stimmelmayr M, Güth J-F, Erdelt K, Edelhoff D, Beuer F. Digital evaluation of the reproducibility of implant scanbody fit - an in vitro study. Clin Oral Investig. 2012;16(3):851-856. doi:10.1007/s00784-011-0564-5

8. Christensen GJ. Will digital impressions eliminate the current problems with conventional impressions? J Am Dent Assoc. 2008;139(6):761-763.

doi:10.14219/jada.archive.2008.0258

9. Chrlstensen GJ. Is the current generation of technology facilitating better dentistry? J Am Dent Assoc. 2011;142(8):959-963. doi:10.14219/jada.archive.2011.0304

10. de Oliveira NRC, Pigozzo MN, Sesma N, Laganá DC. Clinical efficiency and patient preference of digital and conventional workflow for single implant crowns using immediate and regular digital impression: A meta-analysis. Clin Oral Implants Res. 2020;31(8):669-686. doi:10.1111/clr.13604

11. Suese K. Progress in digital dentistry: The practical use of intraoral scanners. Dent Mater J. 2020;39(1):52-56. doi:10.4012/dmj.2019-224

12. M. Zimmermann, A. Mehl, W. H. Mörmann SR. Intraoral scanning systemsa current overview. JInternational ournal Comput Dent. 2015;18(2):101-129.

13. Sinescu C, Negrutiu M, Faur N, Negru R, Romînu M, Cozarov D. Dental scanning in CAD/CAM technologies: laser beams. Lasers Dent XIV. 
2008;6843(February 2008):68430E. doi:10.1117/12.764829

14. Richert R, Goujat A, Venet L, et al. Intraoral Scanner Technologies: A Review to Make a Successful Impression. J Healthc Eng. 2017;2017:1-9. doi:10.1155/2017/8427595

15. RM M, Yilmaz B. Intraoral scan bodies in implant dentistry: A systematic review. J Prosthet Dent TA - TT -. 2018;120(3):343-352. doi:10.1016/j.prosdent.2017.10.029 LK .

16. Carestream Dental LLC CS3600 User and Installation Guide. Cs 3600®. Published online 2020. https://www.carestreamdental.com/en-us/csdproducts/intraoral-scanners/cs-3600-and-cs-scanflow-software/cs-3600-forimplant-borne-restorations/

17. 3D mesh definition. Wikipedia. https://en.wikipedia.org/wiki/Polygon_mesh. Accessed on 04/13/2021.

18. Gheorghe R, Tchouprakov A, Sokolov R. Real-time structured light intraoral 3D measurement pipeline. Real-Time Image Video Process 2013. 2013;8656(February 2013):865609. doi:10.1117/12.2005289

19. Swanson GJ, Kavalauskas MP, Shirley LG. High-precision surface profiling with broadband accordion fringe interferometry. Mach Vis ThreeDimensional Imaging Syst Insp Metrol. 2001;4189(February 2001):161-169. doi:10.1117/12.417193

20. Logozzo S, Zanetti EM, Franceschini G, Kilpelä A. Recent advances in dental optics - Part I : 3D intraoral scanners for restorative dentistry. Opt Lasers Eng. 2014;54:203-221.

21. PiC Dental LLC. https://www.picdental.com/.Accessed on 04/13/2021.

22. Sinescu C, Podoleanu AG, Barua S, et al. Dental impression technique using optoelectronic devices. 2018;(March 2018):8. doi:10.1117/12.2281775

23. ISO-5725-1:1994 . Accuracy (trueness and precision) of measurement 
methods and results - Part 1: General principles and definitions. International Organization for Standardization, Geneva. Accessed on 04/13/2021.

24. 3M ESPE Lava ${ }^{\mathrm{TM}}$ COS Technical Data Sheet. Lava COS Tecnical Data Sheet. Published online 2009.

http://multimedia.3m.com/mws/media/632323O/lava-cos-technical-datasheet.pdf

25. Frigerio F. 3-Dimensional Surface Imaging Using Active Wavefront Sampling PhD Thesis Dissertation. Massachusetts Inst Technol Cambridge $M A$.

26. Lecocq G. Intraoral digital scanner: selection and integration in clinics. $J$ Dentofac Anomalies Orthod. 2016;19(4):402. doi:10.1051/odfen/2018115

27. Fasbinder DJ, Neiva G. Innovations in Digital Technology. Insid Dent CDEWorld. 2021;(September 2014):1-9.

28. Instructions for use. Straumann ${ }^{\circledR}$ Impression Components.

29. Ma T, Nicholls JI, Rubenstein JE. Tolerance Measurements of Various Implant Components. Int J Oral Maxillofac Implants. 1997;12(3):371-375.

30. Michaels GC, Carr AB, Larsen PE. Effect of prosthetic superstructure accuracy on the osteointegrated implant bone interface. Oral Surgery, Oral Med Oral Pathol Oral Radiol Endodontology. 1997;83(2):198-205. doi:10.1016/S1079-2104(97)90006-8

31. Jemt T, Book K. Prosthesis misfit and marginal bone loss in edentulous implant patients. Int J Oral Maxillofac Implants. 1996;11(5):620-625. http://www.quintpub.com/journals/omi/fulltext.php?article_id=4285

32. Pereira L, Sordi M, Magini R. S, Duarte A S. Abutment misfit in implantsupported prostheses manufactured by casting technique: An integrative review. Eur J Dent. 2017;11(4):553-558. doi:10.4103/ejd.ejd

33. Schwarz MS. Mechanical complications of dental implants. Clin Oral Impl 
Res. 2000;11 (Suppl.:156-158.

34. Papaspyridakos P, Chen C-J, Gallucci G, Doukoudakis A, Weber H-P, Chronopoulos V. Accuracy of Implant Impressions for Partially and Completely Edentulous Patients: A Systematic Review. Int J Oral Maxillofac Implants. 2014;29(4):836-845. doi:10.11607/jomi.3625

35. de Araújo Nobre M, Mano Azul A, Rocha E, Maló P. Risk factors of periimplant pathology. Eur J Oral Sci. 2015;123(3):131-139. doi:10.1111/eos.12185

36. Kan JYK, Rungcharassaeng K, Bohsali K, et al. Clinical methods for evaluating implant framework fit. J Prosthet Dent. 1999;81(1):7-13. doi:10.1016/S0022-3913(99)70229-5

37. Choi Y Do, Lee KE, Mai HN, Lee DH. Effects of scan body exposure and operator on the accuracy of image matching of implant impressions with scan bodies. J Prosthet Dent. 2020;124(3):379.e1-379.e6.

doi:10.1016/j.prosdent.2020.04.004

38. CAD file. https://docs.fileformat.com/cad/. Accessed on 04/13/2021.

39. Hammett Patrick C, Garcia-Guzman Luis M, Geddes Steven W WPT. Quantifying Alignment Effects in 3D Coordinate Measurement. Univ Michigan Transp Resesach Inst. 2009;(October).

40. Koch GK, Gallucci GO, Lee SJ. Accuracy in the digital workflow: From data acquisition to the digitally milled cast. $J$ Prosthet Dent. 2016;115(6):749754. doi:10.1016/j.prosdent.2015.12.004

41. Flügge T, van der Meer WJ, Gonzalez BG, Vach K, Wismeijer D, Wang P. The accuracy of different dental impression techniques for implant-supported dental prostheses: A systematic review and meta-analysis. Clin Oral Implants Res. 2018;29(March):374-392. doi:10.1111/clr.13273

42. Jiménez-Gayosso SI, Lara-Carrillo E, López-González S, et al. Difference 
between manual and digital measurements of dental arches of orthodontic patients. Med (United States). 2018;97(22):1-5.

doi:10.1097/MD.0000000000010887

43. ISO 10360 Overview. https://iso10360.wordpress.com/about-2/. Accessed on 04/13/2021.

44. van der Meer WJ, Andriessen FS, Wismeijer D, Ren Y. Application of intraoral dental scanners in the digital workflow of implantology. PLoS One. 2012;7(8):1-8. doi:10.1371/journal.pone.0043312

45. Ender A, Mehl A. Accuracy of complete-Arch dental impressions: A new method of measuring trueness and precision. J Prosthet Dent. 2013;109(2):121-128. doi:10.1016/S0022-3913(13)60028-1

46. Flügge T V., Schlager S, Nelson K, Nahles S, Metzger MC. Precision of intraoral digital dental impressions with iTero and extraoral digitization with the iTero and a model scanner. Am J Orthod Dentofac Orthop. 2013;144(3):471-478. doi:10.1016/j.ajodo.2013.04.017

47. Mizumoto RM, Yilmaz B, McGlumphy EA, Seidt J, Johnston WM. Accuracy of different digital scanning techniques and scan bodies for complete-arch implant-supported prostheses. J Prosthet Dent. 2020;123(1):96-104. doi:10.1016/j.prosdent.2019.01.003

48. Gimenez-Gonzalez B, Hassan B, Özcan M, Pradíes G. An In Vitro Study of Factors Influencing the Performance of Digital Intraoral Impressions Operating on Active Wavefront Sampling Technology with Multiple Implants in the Edentulous Maxilla. J Prosthodont. 2017;26(8):650-655. doi:10.1111/jopr.12457

49. Batak B, Yilmaz B, Shah K, Rathi R, Schimmel M, Lang L. Effect of coded healing abutment height and position on the trueness of digital intraoral implant scans. J Prosthet Dent TA - TT -. 2020;123(3):466-472. 
doi:10.1016/j.prosdent.2019.06.012 LK -

50. Çakmak G, Yilmaz H, Treviño A, Kökat AM, Yilmaz B. The effect of scanner type and scan body position on the accuracy of complete-arch digital implant scans. Clin Implant Dent Relat Res. 2020;22(4):533-541. doi:10.1111/cid.12919

51. Fluegge T, Att W, Metzger M, Nelson K. A Novel Method to Evaluate Precision of Optical Implant Impressions with Commercial Scan Bodies-An Experimental Approach. J Prosthodont. 2017;26(1):34-41. doi:10.1111/jopr.12362

52. Matta RE, Adler W, Wichmann M, Heckmann SM. Accuracy of impression scanning compared with stone casts of implant impressions. J Prosthet Dent. 2017;117(4):507-512. doi:10.1016/j.prosdent.2016.07.026

53. Kim J-H, Kim KR, Kim S. Critical appraisal of implant impression accuracies: A systematic review. J Prosthet Dent. 2015;114(2):185-192.e1. doi:10.1016/j.prosdent.2015.02.005

54. Giménez B, Özcan M, Martínez-Rus F, Pradíes G. Accuracy of a Digital Impression System Based on Parallel Confocal Laser Technology for Implants with Consideration of Operator Experience and Implant Angulation and Depth. Int J Oral Maxillofac Implants. 2014;29(4):853-862. doi:10.11607/jomi.3343

55. Nedelcu RG, Persson ASK. Scanning accuracy and precision in 4 intraoral scanners: An in vitro comparison based on 3-dimensional analysis. J Prosthet Dent. 2014;112(6):1461-1471. doi:https://doi.org/10.1016/j.prosdent.2014.05.027

56. Motel C, Kirchner E, Adler W, Wichmann M, Matta RE. Impact of Different Scan Bodies and Scan Strategies on the Accuracy of Digital Implant Impressions Assessed with an Intraoral Scanner: An In Vitro Study. $J$ 
Prosthodont. 2020;29(4):309-314. doi:10.1111/jopr.13131

57. Wulfman C, Naveau A, Rignon-Bret C. Digital scanning for complete-arch implant-supported restorations: A systematic review. J Prosthet Dent. 2020;124(2):161-167. doi:10.1016/j.prosdent.2019.06.014

58. Lee J-H, Yun J-H, Han J-S, Yeo I-SL, Yoon H-I. Repeatability of Intraoral Scanners for Complete Arch Scan of Partially Edentulous Dentitions: An In Vitro Study. J Clin Med. 2019;8(8):1187. doi:10.3390/jcm8081187

59. Waldecker M, Rues S, Rammelsberg P, Bömicke W. Accuracy of completearch intraoral scans based on confocal microscopy versus optical triangulation: A comparative in vitro study. J Prosthet Dent. Published online 2020:1-7. doi:10.1016/j.prosdent.2020.04.019

60. Mutwalli H, Braian M, Mahmood D, Larsson C. Trueness and Precision of Three-Dimensional Digitizing Intraoral Devices. Int J Dent. 2018;2018. doi:10.1155/2018/5189761

61. Miyoshi K, Tanaka S, Yokoyama S, Sanda M, Baba K. Effects of different types of intraoral scanners and scanning ranges on the precision of digital implant impressions in edentulous maxilla: An in vitro study. Clin Oral Implants Res. 2020;31(1):74-83. doi:10.1111/clr.13548

62. Kurz M, Attin T, Mehl A. Influence of material surface on the scanning error of a powder-free 3D measuring system. Clin Oral Investig. 2015;19(8):20352043. doi:10.1007/s00784-015-1440-5

63. Rapone B, Palmisano C, Ferrara E, Di Venere D, Albanese G, Corsalini M. The accuracy of three intraoral scanners in the oral environment with and without saliva: A comparative study. Appl Sci. 2020;10(21):1-20. doi:10.3390/app10217762

64. Tan M, Yee S, Wong K, Tan Y, Tan K. Comparison of Three-Dimensional Accuracy of Digital and Conventional Implant Impressions: Effect of 
Interimplant Distance in an Edentulous Arch. Int J Oral Maxillofac Implants. 2019;34(2):366-380. doi:10.11607/jomi.6855

65. Giménez B, Özcan M, Martínez-Rus F, Pradíes G. Accuracy of a Digital Impression System Based on Active Wavefront Sampling Technology for Implants Considering Operator Experience, Implant Angulation, and Depth. Clin Implant Dent Relat Res. 2015;17:e54-e64. doi:10.1111/cid.12124

66. Chia V, Esguerra R, Teoh K, Teo J, Wong K, Tan K. In Vitro ThreeDimensional Accuracy of Digital Implant Impressions: The Effect of Implant Angulation. Int J Oral Maxillofac Implants. 2017;32(2):313-321. doi:10.11607/jomi.5087

67. Moslemion, M., Payaminia, L., Jalali, H., Akhilasi M. Do Type and Shape of Scan Bodies Affect Accuracy and Time of Digital Implamt Impressions? Eur J Prosthodont Restor Dent. 2020;28(1):18-27. doi:10.1922/EJPRD

68. Wismeijer D, Joda T, Flügge T, et al. Group 5 ITI Consensus Report: Digital technologies. Clin Oral Implants Res. 2018;29(May):436-442. doi:10.1111/clr.13309

69. Wesemann C, Kienbaum H, Thun M, Spies BC, Beuer F, Bumann Mesantis 3D Dental-Radiology, Berlin, Germany AP and D of 3D I. Does ambient light affect the accuracy and scanning time of intraoral scans? J Prosthet Dent TA - TT -. Published online 2020. doi:10.1016/j.prosdent.2020.03.021 LK

70. Revilla-León M, Subramanian SG, Att W, Krishnamurthy VR. Analysis of Different Illuminance of the Room Lighting Condition on the Accuracy (Trueness and Precision) of An Intraoral Scanner. J Prosthodont. 2021;30(2):157-162. doi:10.1111/jopr.13276

71. Koseoglu M, Kahramanoglu E, Akin H. Evaluating the Effect of Ambient and Scanning Lights on the Trueness of the Intraoral Scanner. J Prosthodont. 
2021;0:1-6. doi:10.1111/jopr.13341

72. Lee H, Ercoli C, Funkenbusch PD, Feng C. Effect of subgingival depth of implant placement on the dimensional accuracy of the implant impression: An in vitro study. J Prosthet Dent. 2008;99(2):107-113. doi:10.1016/S00223913(08)60026-8

73. Zfx Scan III. https://zfx-dental.co.uk/products/zfx-scan-iii/. Accessed on $03 / 21 / 2021$.

74. Park SW, Choi Y Do, Lee DH. The effect of the improperly scanned scan body images on the accuracy of virtual implant positioning in computeraided design software. $J$ Adv Prosthodont. 2020;12(3):107-113. doi:10.4047/jap.2020.12.3.107

75. Giménez B, Özcan M, Martínez-Rus F, Pradíes G. Accuracy of a Digital Impression System Based on Active Triangulation Technology With Blue Light for Implants. Implant Dent. 2015;24(5):498-504.

doi:10.1097/ID.0000000000000283

76. Mangano FG, Admakin O, Bonacina M, Lerner H, Rutkunas V, Mangano C. Trueness of 12 intraoral scanners in the full-arch implant impression: A comparative in vitro study. BMC Oral Health. 2020;20(1):1-21.

doi:10.1186/s12903-020-01254-9

77. Imburgia M, Logozzo S, Hauschild U, Veronesi G, Mangano C, Mangano FG. Accuracy of four intraoral scanners in oral implantology: A comparative in vitro study. BMC Oral Health. 2017;17(1):1-13. doi:10.1186/s12903-0170383-4 